Hartwig Kalverkämper*

\title{
Im Zentrum der Interessen: Fachkommunikation als Leitgröße
}

\section{Fachlichkeit und Fachsprachlichkeit als mentalitätsgeschi- chtliche Größe}

2. Fachlichkeit und Fachsprachlichkeit als soziale Führungsgröße

2.1. 'Fach'-Begriff

2.2. Kontroverse, Brisanz, Schwere, Regelung

2.3. Fachlichkeit durch Fachsprachlichkeit

2.4. Graduelle Stufung von Fach(sprach)lichkeit: Skala

2.5. Innersprachliche Kontakte

2.5.1. Verständlichkeit

2.5.2. Forschungsumfeld

2.5.3. 'Technische Kommunikation' / 'Technical Writing'

2.5.4. Strategie 'Erklären'

2.5.5. Textsorte 'Sachbuch'

2.5.6. Fachsprachen-Hermeneutik

2.6. Zwischen- / fremdsprachliche Kontakte

2.6.1. Deutsch als Fremdsprache

2.6.2. Übersetzen

2.6.3. Anglophonie in den Wissenschaften

Vorbemerkung:

Dieser Aufsatz ist die wesentlich erweiterte und bibliographisch aufbereitete Fassung meines einstündigen Plenumsvortrags "Die Fachsprachen und ihre Erforschung - Eine Bilanz für die Zukunft" anläßlich des X. European Symposium on Language for Special Purposes 'LSP': 'Multilingualism in Specialist Communication / Multilinguisme dans la communication spécialisée / Mehrsprachigkeit in der Fachkommunikation', Vienna/Wien, 29.8. - 1.9.1995. Die Vortragsversion erscheint in dem Sonderheft 2 (1996) "Proceedings of the Tenth European Symposium on LSP" der Wiener Zeitschrift Fachsprache / International Journal of LSP.

* Hartwig Kalverkämper

Humboldt-Universität

Institut für Romanistik

Unter den Linden 6

D-10099 Berlin

Hermes, Journal of Linguistics no. 16 - 1996 
3. Fachlichkeit und Fachsprachlichkeit als forschungsrelevante Größe (Methodologie)

3.1. Fachgebundenheit / Sachbezogenheit

3.2. Systematizität

3.3. Medialität

3.4. Chronizität (Syn- / Diachronie)

3.5. Applikabilität (Gesellschaftsbezug)

3.6. Semiotizität

3.7. Kontrastivität

3.7.1. Intertextualität

3.7.2. Interdisziplinarität

3.7.3. Interkulturalität

4. Fachlichkeit und Fachsprachlichkeit als Zukunftsgröße

4.1. Anspruchsgröße

4.2. Reflexionsgröße

4.3. Integrationsgröße:

'Fachsprachen-in-Texten-und-Kommunikationssituationen-und-Kultur'

5. Ausblick: Fachkommunikation

\section{Literaturverzeichnis}

\section{Fachlichkeit und Fachsprachlichkeit als mentalitätsge- schichtliche Größe}

Wer im Kunsthistorischen Museum von Wien die Ephesos-Sammlung besucht, wird dort unter der Inventar-Nummer 159 eine Dame antreffen, die an die wohl mehr als zweitausend Jahre alt ist und aus der südlichen Nische der Celsus-Bibliothek in Ephesos, Kleinasien, stammt. ${ }^{1}$ Die lebensgroße Skulptur ist die hellenistische Personifikation von $\Sigma o \varphi^{\prime} 1 \alpha$, Sophía (3. Jahrh. v. Chr.), allerdings in römischer Kopienfassung aus dem 2. Jahrhundert n. Chr. ${ }^{2}$ Die marmorne Sophía ist mit dem typischen griechischen, wollenen Frauengewand, dem zylindrisch über die Schultern gelegten, rechts offenen Peplos, und mit einem Mantel bekleidet, trägt Sandalen und stützt sich auf ihr rechtes Bein. Ihr Kopf richtet sich etwa drei Viertel nach links. Der Blick wandert aus dem an Nase und Wangen beschädigten Gesicht horizontal in die Ferne. Der Statue fehlen der rechte Arm und der linke Unterarm, so daß wir nicht wissen, ob und was die Sophía in ihren Händen gehalten haben mag. 
Eine Vermutung dazu läßt die römische Kopie im Pariser Louvre mit der Inventar-Nummer $170^{3} \mathrm{zu}$ : Stark nach rechts mit erhobenem Haupt weiter als über die Horizontale in die Ferne schauend, hält sie mit angewinkeltem Arm vor ihrer linken Brust eine Papyrusrolle in der Hand. Auf dieser, so soll wohl bedeutet werden, ist das Wissen der Zeit niedergeschrieben und zur Weitergabe, der traditio oder translatio, gesichert.

Bilder, Reliefs, Skulpturen oder Plastiken der Sophía als weiblich personifizierte 'Weisheit' sind in der Antike nicht häufig und finden sich dann auch erst ab der hellenistischen Zeit (4. Jahrhundert ${ }^{4}$ bis Christi Geburt), nachdem die Dichter und Denker der davorliegenden klassischen Zeit (5. Jahrhundert bis ca. zweites Viertel 4. Jahrhundert) ${ }^{5}$ sie aus ihrer reinen Begrifflichkeit befreit und personifiziert hatten (Aristophanes, Euripides u.a.).

Die Papyrusrolle als allegorisches Attribut sagt allerdings nur wenig aus gegenüber dem komplexen Bedeutungsumfang, den griech. sophía meint: 'Wissen', 'Weisheit' und 'Wissenschaft' sind gleichermaßen darin beschlossen. Grundlage dieses wohl wichtigsten Begriffs des Griechentums ${ }^{6}$ sind das Kundigsein, das Beherrschen von Fachlichkeiten, die Könnerschaft, die "auf Sachkunde und Wissen beruhende Tüchtigkeit, die den einzelnen aus der Menge hervorhebt"7. Diese Eigenschaft galt zu Zeiten des Homer unabhängig von der Tüchtigkeit der Hände, also dem Handwerk, der téchne, griech. $\tau^{\prime} \varepsilon \chi v \eta$, wie dem von Homer erwähnten - Zimmermann, oder des Kopfes, mit dem man als Staatsmann, Richter, Gesetzgeber, Denker, Erfinder oder Dichter "tiefere Einsicht in den Zusammenhang der Dinge und die Aufgaben des Lebens", also die epistéme, erlangte. Können und Wissen sind hier ganz der praktischen Umsetzbarkeit verpflichtet.

Und so erhält sophía dann bei den Vorsokratikern des 6. Jahrhunderts v. Chr. ${ }^{8}$ die Konturierung, daß sie eine "bewußte, auf Wissen gegründete Lebensgestaltung im Gegensatz zum Zufall, zur $\tau v \chi \eta^{\text {“9, }}$, meint.

Sophía als Begriff für - modern gesagt - 'Sachwissen', 'systematische Einsicht' und 'kriteriengeleitete Gestaltung', also sophía als nochmals mit heutigen Worten - ein Begriff der fachlichen Exponiertheit, des persönlichen Ausweises durch Wissen, Weisheit, Wissenschaft einerseits und Können, Kenntnis, Fachkunde andererseits war den Denkern des dann folgenden klassischen Zeitalters (5. und 4. Jahr- 
hundert v. Chr. ${ }^{10}$ ) zu überheblich: diese Fähigkeiten, Qualitäten und Könnerschaften, diese sophía, könne der Mensch nicht für sich in Anspruch nehmen, geschweige wirklich besitzen, vielmehr kommen sie allein den Göttern zu, und der Mensch muß sich bescheiden im Streben und in der freundschaftlichen Annäherung an die sophía, eben als ihr philos zufrieden sein mit der Vorstufe der angezielten sophía, mit der philo-sophía.

Mit diesem Ansatz ist die sophía theologisch erhöht ${ }^{11}$, der auf menschliches Wirken und Können zielende, auf sein handwerkliches wie intellektuelles Fachwissen gründende Begriff wird durch den fachlichen Ausweis der Kenntnisse und Könnerschaft der Götter relativiert. Die so theologisch sublimierte Sophía erhält Partner ihrer Vollkommenheit: sie zeigen sich in den allegorischen Marmorfiguren, wie sie ebenfalls in den Fassadennischen der Celsus-Bibliothek oder an der Freitreppe auf dem Markt von Ephesos standen - und nun ebenfalls in Wien, Ephesos-Museum, zu bewundern sind: nämlich ${ }^{12}$

die Epistéme, griech. E $\pi \iota \sigma \tau$ ' $\mu \eta$ ('Wissen', 'Kenntnis', 'Einsicht', 'Geschicklichkeit', 'Fertigkeit', 'Wissenschaft') ${ }^{13}$,

die Areté, griech. A $\rho \varepsilon \tau$ ' $\eta$ ('Tüchtigkeit', 'Tugend', 'Verstand', 'Können', 'Geschicklichkeit'; jede wertvolle Eigenschaft an Gestalt und Charakter, Verstand und Können) ${ }^{14}$,

und die Énnoia, griech. 'Evvor $\alpha$ ('Gedanke', 'Vorstellung', 'das Nachdenken') ${ }^{15}$.

Dieser Reigen vierer Personifizierungen von Eigenschaften und Merkmalen des Wissens und Könnens bezeugt den gezielten Blick der Alten auf das im Handeln ausgewiesene Besondere und belegt somit auch die herausragende Wertstellung eines solchen Handelns in der antiken Gesellschaft.

Die antiken Personifikationen des Wissens - und in dessen Gefolge und Umkreis: der Weisheit und der Wissenschaft - heben eine mentalitätsgeschichtlich brisante Größe der Conditio humana in den Blick. Für die griechische Geisteswelt und Lebenspraxis stehen diese Allegorien hier wie ein Programm, dem das Abendland eine kraftvolle, kohärente und fruchtbare Tradition und eine kulturelle Identität verdankt, und dieses Programm heißt: Philosophie.

Sie ist als 'Liebe zur Weltweisheit' und somit als 'geistiges Streben', 'wissenschaftliche Betätigung', ja 'Forschung', der Begriff, geradezu 
der Inbegriff dessen, was durch spezielles Wissen und Können aus dem Alltag hebt, ausgrenzt, besonders macht. Sie steht also, am Anfang der Kulturgeschichte des Geistes, für ein (vierpersonal) gegliedertes Bewußtsein von Fachlichkeit.

Die antike Philosophie und ihre göttlichen Verwandten - die Sophía, die Epistéme, die Areté und die Énnoia - sind die mentalitätsgeschichtlich fundamentalen Ausprägungen am Beginn von Verbesonderung im Handeln, also: von Fachlichkeit, von Spezialisierung im Denken, im Ausbau von Geisteskultur, und somit in der Weitergabe intellektueller und theoretisierender Erkenntnisse.

Das Manuelle, auf Wirken mit den Händen, 'Hand-Werk' bezogene Seitenstück dazu hatte, wie erwähnt, nur zu homerischen Zeiten den sophía-Begriff belebt (Homer bezieht, wie gesagt, den Zimmermann ausdrücklich mit ein). Das Wissen und Können durch Muskelkraft, Beobachten der Natur, Umsetzen des Erfahrungsschatzes in ständig verbesserte Kunstfertigkeit, was die Griechen $\tau^{\prime} \varepsilon \chi \vee \eta$, téchne, nannten, im Sinne von 'Geschicklichkeit', 'Handwerk', dabei auch 'geistige Gewandtheit', nahm sein Maß nicht an der weiten, horizontgerichteten Blickferne der bei Aristoteles zu einer Kategorie der Entrückung und Vollkommenheit ('Weisheit') gereiften Sophía, und nicht an ihrer statuarischen Haltung, mit der sie zeigt, daß sie in sich ruht als

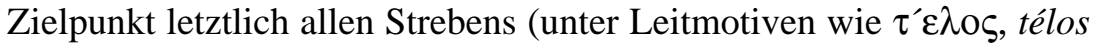
'Ziel'; $\alpha \gamma \alpha \vartheta$ 'ov, agathón 'Gut', 'Wohltat'; und ov $\sigma^{\prime} 1 \alpha$, ousía 'Sein', 'Wesen') ${ }^{16}$. Vielmehr orientierte sich der Begriff der handwerklichen Könnerschaft an der wirklichkeitsnahen Anschauung, an der Begrenztheit des Lebenshorizontes und an den Abläufen der Alltagsnotwendigkeiten, indem nämlich das wichtigste Bauelement, das Fach, der Kasten also zum Fangen, Aufbewahren, Abstützen, Aufbauen, Schützen, begrifflich prägend wirkte und darin mentalitätsgeschichtlich entscheidende Akzente setzte: 17

Was hier die vorzeitlichen Bauhandwerker, Fischer, Bauern und Bergleute für ihre Zwecke wie Fachwerkbau (Zaun, Mauer, Haus), Wehrbau, Fangkästen (Fischerei, Niederwild) und Speicherkisten (Landwirtschaft, Hauswirtschaft) herstellten, war begrifflich in der indogermanischen Sprachwurzel *pag- oder *pak- gebunden. Im Griechischen setzt sie sich fort in dem Handwerk-Wort $\pi^{\prime} \eta \gamma \nu v v \alpha \imath$ pégnynai 'festmachen', 'zusammenfügen', 'befestigen', im Lateinischen gleichbedeutend in pangere, dessen Substantiv pagus dann schon 
von der handwerklichen Zaun- und Wand-Begrifflichkeit metaphorisch ausgreifend 'Gau', 'Gemeinde' bezeichnete, dann im Romanischen die abgrenzende Vorstellung in der Bedeutung von 'Land' weitergab mit franz. pays, span./port. país, ital. paese. Im Germanischen hat sich die indogermanische Wurzel mit Formen wie altsächs. fac, angelsächs. foec, althochdt. fah zu dt. Fach, schwed. fack usw. entwickelt. In beiden Entwicklungssträngen, dem romanischen und dem germanischen, wird der ursprüngliche arbeitsweltliche Gehalt des Einrammens von raummarkierenden Pfosten und des verflechtenden Zusammenfügens zu Zaun und - mit Lehmverschmierung dann - zu Wand und Mauer noch deutlich, wenn man dabei die eigentlichen Funktionen solcher Tätigkeiten mitsieht: nämlich das Eingrenzen nach innen und damit zugleich das Ausgrenzen nach außen. ${ }^{18}$

Diese Grundvorstellung hat sich als eine mentalitätsgeschichtliche Konstante unserer abendländischen Kultur bis heute im 'Fach'-Begriff erhalten: die "Wir vom Bau"-Mentalität, die ausgrenzende Macht durch Fachwissen, die Expertokratie bestimmen das Miteinander der Berufsund Fachgruppen in den modernen arbeitsteiligen Gesellschaften; die gegensteuernden Rufe nach Transparenz, Kooperation und Durchlässigkeit zwischen den Fächern offenbaren, wie beherrschend diese Urerfahrungen sind. Sie sind sozialgeschichtliche Prägungen, denen sich die Menschheit dieser Hemisphäre in den fünf- bis sechstausend Jahren seit der indogermanischen Sprachperiode oder in den dreitausend Jahren ab der früharchaischen Zeit (Homer, 8. Jahrhundert v. Chr.) offensichtlich nicht entzogen hat.

In ihnen liegt noch eine andere mentalitäts- und somit auch sozialgeschichtlich entscheidende Größe beschlossen: Der Begriff des Fortschritts ${ }^{19}$, der eng an das Selbstverständnis der manuellen, konkreten fachlichen Tätigkeiten und der intellektuellen, fachtheoretisierenden Erkenntnisanstrengungen der Philosophie gebunden ist. Die kulturelle translatio - die translatio artium oder translatio studii - als die Weitergabe von erarbeitetem Wissen ist ein Gedankenmodell, das von den Römern, hier insbesondere von Cicero, gepflegt wurde, dabei durchaus in selbstkritischer Distanz zu den eigenen Kulturleistungen, die ja den Griechen so viel verdankten. So schien es, daß das Erringen fachlichen, spezifischen Wissens - griech. sophía, lat. sapientia - von den Ägyptern als den Urhebern, den inventores (griech. $\varepsilon v \rho \varepsilon \tau \alpha l$ heuretai) großer denkerischer Kulturleistungen, weitergegeben worden 
war an die Griechen als Empfänger, von diesen dann weitergereicht wurde an die Römer, im Sinne einer Aneignung (lat. aemulatio) griechischen Denkens und Könnens. ${ }^{20}$

Hier kommt ein Gesichtspunkt, die 'Bildung' und, in sozialer Verantwortung einer translatio: die 'Ausbildung', ins Spiel, der als Unterrichtskanon die Fächer, also eingrenzende und abtrennende Einteilungen des komplexen Wissens, vorgab und damit die intellektuelle und die manuelle fachliche Tätigkeit um die lehrende Tätigkeit ergänzte. Die Philosophie hat diese Gemeinschaft seit ihren Anfängen vorgeführt. Sie hat dabei dann auch deutlich werden lassen, daß für ein geschärft reflektierendes Annähern an die Wahrheit eine eigene Begrifflichkeit, ein spezielles fachliches Instrumentarium also, notwendig ist, bis hin zu prädestinierten Textsorten wie den (philosophischen) Dialogen. Und wachsende Erkenntnis muß dann auch in spezieller Zuwendung gelehrt und weitergegeben werden. Fachbezogener Unterricht ist demnach ein Bildungsgut, fachliche Ausbildung ein Lehrziel.

Nur: Vor diesem seit alters her offenkundig sinnvollen und praktizierten Prinzip ändern sich der Umfang des Lehrstoffes und die Wege - 'Methoden' - des Lehrens im Laufe der Zeiten. So war seit spätlateinischer und in mittelalterlicher Zeit das umfassend zu unterrichtende Wissen eingebunden in den soziokulturell verfestigten Rahmen der artes. Ars, Plural artes, liegt begrifflich (analog zu griech. $\tau^{\prime} \varepsilon \chi \vee \eta$ ) nahe an der manuell ausgerichteten spezifischen, eben fachlichen Tätigkeit mit Bedeutungen wie 'Geschick', 'Fertigkeit', 'Gewandtheit', 'Kunstwerk', metonymisch 'Handwerk', 'Gewerbe', verweist aber mit Attributen wie (artes) optimae 'Wissenschaften' oder urbanae 'Ius und Redekunst' und in der absetzenden Gemeinschaft mit disciplina (artes et disciplina) als dem 'praktischen Unterricht' (gegenüber artes als dem 'theoretischen Unterricht') auch deutlich auf die sophía- oder eher philosophía-Komponente menschlichen Handelns, eben mit den Bedeutungen 'Wissenschaft', metonymisch 'Theorie'.

So hat die Antike selbst - so Aristoteles in der "Nicomachischen Ethik", Cicero im “Brutus" $(29,111)$ oder Quintilian in der "Institutio oratoria” (II 17, 41) - die artes als ein System verstanden, dem Erfahrungswerte (Empirie; griech. $\varepsilon \mu \pi \varepsilon 1 \rho^{\prime} \imath \alpha$ 'Erfahrung', 'Kenntnis') zugrundelagen, welche ihrerseits in ihrer Regelmäßigkeit, ihrer Geregeltheit erkannt wurden und dann weiterentwickelt wurden $\mathrm{zu}$ 
logisch durchdachten, lehrhaften Regeln (lat. praecepta, regulae), mit denen wiederholbare, richtig durchgeführte Handlungen aus dem Willen des handelnden Menschen vorgeschrieben, gesteuert, d. h. gelehrt (lat. doctrina) bzw. gelernt und somit erwartbar gemacht wurden.

In dieser Abfolge - also durch regulae mit doctrina zur Erlernung der ars - kommt man zur scientia, also zum 'Wissen', zum Schatz fachlicher Könnerschaft, also zur 'Wissen-schaft', was dann entsprechend in die Tat umgesetzt werden muß, und zwar als facultas, als 'Können'. 21 Hier liegt, mentalitätsgeschichtlich als die Anfänge unseres abendländischen Kulturbewußtseins im Umfeld von sophíal sapientia und téchnelars, eine pragmatisch fundierte Kette fachlicher Rezeption, Reflexion, Systematisierung und Applikation vor, die als solche den herausragenden Stellenwert der Fachlichkeit in der Kulturund Menschheitsgeschichte (zumindest der westlichen Hemisphäre) markiert.

Die artes der Antike, der Spätantike und des Mittelalters als dem Lehrprogramm fachbezogenen Wissens, fachlichen Könnens und fachspezifischen Ausbildens umfaßten als primäre die artes liberales, griech. $\tau^{\prime} \varepsilon \chi \nu \alpha \imath \varepsilon \gamma \kappa^{\prime} v \kappa \lambda$ เor téchnai enkyklioi, also die "enzyklopädischen", d.h. 'kreisförmig' angelegten, allgemeinbildenden Wissenschaften (griech. $\varepsilon \gamma \kappa^{\prime} v \kappa \lambda 10 \varsigma \pi \alpha 1 \delta \varepsilon^{\prime} 1 \alpha$ enkyklios paidéia) oder "freien Künste", die den freien (liberales) Bürgern, der gesellschaftlichen Oberschicht, vorbehalten waren: ab der Spätantike und mit dem Mittelalter zählten verbindlich sieben artes hierzu: grammatica, rhetorica und dialectica als das "geisteswissenschaftliche", formal-sprachliche Trivium (ab 9. Jahrhundert), und arithmetica, musica, geometria und astronomia als das "naturwissenschaftliche", mit Maßen arbeitende Quadrivium (ab Anfang 6. Jahrhundert). ${ }^{22}$ Diese Künste bildeten den propädeutischen Unterbau im Lehrbetrieb der Artistenfakultät mittelalterlicher Universitäten und waren Voraussetzung für den StudienEinstieg in eine höhere Fakultät. ${ }^{23}$

Diese gelehrten artes wurden ergänzt durch die auf Gelderwerb gerichteten, also handwerklichen Fertigkeiten und Fachkenntnisse, durch die artes mechanicae (griech. $\tau^{\prime} \varepsilon \chi v \alpha \mathrm{l} \beta^{\prime} \alpha v \alpha v \sigma o r$ téchnai bánausoi), die "Eigenkünste" (Eis 21967), wozu in den meisten mittelalterlichen Wissenschaftslehren Handwerk (lat. opificium u.a.), Kriegswesen (armatura), Seefahrt und Erdkunde (navigatio), Landbau 
und Handel (agricultura), Tiere und Wald (venatio), natürlich auch die Heilkunde (medicina) und die Hofkünste (theatrica) gehörten. ${ }^{24}$

Schließlich noch die aus mittelalterlicher Weltsicht sogenannten "verbotenen Künste" (artes incertae [gemäß Paracelsus]), so Magie und Mantik und Gaunertum.

Für die Bildung durch Lehrplan und Unterricht in Fächern bleiben die sieben artes liberales trotz Kritik und verschiedener Eingriffe ${ }^{25}$ die Grundlage der christlich-abendländischen Fach-Lehre bis zu Beginn der Neuzeit, also als Unterrichtsmodell immerhin etwa tausend Jahre lang, bis sie vom modernen Weltbild und von den umwälzenden Entwicklungen in den Wissenschaften als schulischer und universitärer Lehrplan verdrängt wurden.

Die translatio studii, also die Weitergabe von Wissen, ist von Griechenland über Rom weiter nach Norden gelangt, nach Frankreich und Deutschland, wodurch sich die Ost-West-Bewegung schloß. Kulturgeschichtlich und speziell mentalitätsgeschichtlich und, darin beschlossen, natürlich sozialgeschichtlich hat sich daraus ein starkes Bewußtsein von Kulturengemeinschaft, von geschichtlicher Kontinuität im Geben und Nehmen fachlicher theoriegerichteter Erkenntnisse und fachbezogener praktischer Könnerschaften entwickelt. Die Aufklärungszeit im 18. Jahrhundert führt in ihrem Verständnis von 'Philosophie' die antike Offenheit fachlichen Erkenntnisinteresses weiter: "chez certains auteurs [...] [la] catégorie [scil. 'Sciences et Arts'] s'identifie avec la philosophie en raison de la tradition: 'Philosophia comprehendit artes et scientias'."26 Man spricht vom Zeitalter der Aufklärung als einem "siècle philosophe, dem die Wissenschaften auch Organ und Ziel eines praktisch gearteten Erkennens geworden sind" (Schalk 1968: 259).

So sichtet und kompiliert das 18. Jahrhundert das bislang Beobachtete, Erkannte und Erforschte, wie die berühmte "Encyclopédie, ou Dictionnaire raisonné des Sciences, des Arts et des Métiers" von Diderot und D'Alembert (Paris 1751 - 1780) beweist, und versucht, Ordnung nach wissenschaftlichen Maßgaben in die Menge an Wissen zu zwingen, was sich besonders deutlich in den neuen Nomenklaturen der Botanik, Zoologie und Chemie zeigt.

Die historische Kontinuität geistiger wie praktischer Leistungen war damit zwischen Antiqui und Moderni gewahrt, ohne einen Stillstand zu erzeugen, man saß, um ein Bild des Frühscholastikers Bernhard von 
Chartres $(\dagger 1130)$ aufzunehmen, als 'Zwerge auf den Schultern von Riesen', d.h. der Vorfahren, - nani gigantium humeris insidentes - und war dadurch imstande, von solcher höheren Warte aus weiter und umfassender zu schauen als die Vorfahren. ${ }^{27}$

Danach, so scheint mir, verlieren das fachliche Denken (die sophía, eher die philo-sophía) und das fachliche Handeln und Wirken (die téchne oder ars) ihre kulturhistorische Filiation. Das liegt wohl begründet in dem Mentalitätsumschwung und dem tiefen Sozialumbruch der Industriellen Revolution in der ersten Hälfte des 19. Jahrhunderts als Bewußtsein des fachlich denkenden und tätigen Menschen und seiner neu zu definierenden Stellung zur Maschine (damals: Dampfmaschine). An die Stelle der sophía ist ein radikaler Begriff von 'Fortschritt' getreten, der sich auf 'Vermehrung', 'Wachstum', 'Zunahme', 'Anwachsen' richtet, weniger auf 'Gedeihen', wie bei den Griechen die $\pi \rho \kappa_{0} \pi^{\prime} \eta$ prokopé, bei Cicero der progressus (lat. auch profectus).

Die technischen und wissenschaftlichen Entwicklungen nach dem Zweiten Weltkrieg mit Automatisation, Kernenergie, Telekommunikation und Elektronik als der inzwischen sogenannten Zweiten Industriellen Revolution staffeln sich schon nach in Dekaden faßbaren Innovationsschüben wie: in den vierziger Jahren die Kunststoffe; in den fünfziger Jahren die Transistoren; in den sechziger Jahren die Computer; in den siebziger Jahren dann die Mikroprozessoren; in den achtziger Jahren die Gentechnologie; und in unseren Neunzigern die gesamte Mikroelektronik, möglicherweise schon jetzt in ihrer Schlüsselstellung unter den Technologien - Konsum- und Unterhaltungssowie Medientechnik, Datenverarbeitung und Dokumentation, Nachrichtentechnik / Telekommunikation, Genforschung, Medizin (apparativ, therapeutisch, dokumentativ), Verkehrswesen (Fahrzeugtechnik, Organisation, Entwicklung), Umwelttechnologie, Militär, Industrie (Roboter; intelligente Systeme bei Entwicklung, Fertigung, Kontrolle) usw. - etikettierbar als die Dritte Industrielle Revolution.

Diese Rasanz verschüttet die mentalitätsgeschichtlichen Implikate und läßt lediglich zu, nach dem Stellenwert der ehemals über sophía, epistéme und téchne gewachsenen Größe 'Fach', 'Fachlichkeit', 'fachbezogenes Denken' und 'fachliches Handeln' im aktuellen gesellschaftlichen Umfeld und modernen arbeitswirkenden Geschehen zu fragen. 
Diese Herausforderung führt uns somit weg von der begriffs- und mentalitätsgeschichtlichen Größe zu dem nächsten Komplex, der Fachkommunikation als sozialer Führungsgröße.

\section{Fachlichkeit und Fachsprachlichkeit als soziale Führungsgröße}

\section{1. 'Fach'-Begriff}

Da menschliche Gemeinschaften, als homo sociologicus, immer auch handelnde Gemeinschaften, als homo faber, sind und dies ausführen als sprechende, kommunizierende Gemeinschaften, als homo loquens, prägen sich kulturhistorisch mächtige, weil letztlich anthropologische Züge natürlich auch sprachlich, besser: in den Sprachen der Gemeinschaften aus. Hier brauchen wir uns nur an eine der fundamentalen Tätigkeiten der ersten téchne erinnern, nämlich an das Erstellen von Abtrennungen und Kästen, was mit den urhandwerklichen Arbeiten des Einrammens, Verflechtens und Zusammenfügens zu Fächern, Gefachen, Fachwerk verbunden ist, um die kulturanthropologische Dimension von 'Fachlichkeit' zu sehen. 28

Und so haben wir in den modernen Gesellschaften des hiesigen (im weitesten Sinn "europäischen" oder mit dem althergebrachten Kulturbegriff: "abendländischen") Kulturkreises ${ }^{29}$ einen relativ konsentiell eingeschätzten Begriff dessen, was eine Handlung als fachliche, eine Tätigkeit als fachbezogene, eine Arbeit als berufliche ausmacht, nämlich

- ihr Selbstverständnis als systematisch, als gegenseitig strukturbezogen, eingebettet in eine übergeordnete Ganzheit, die als solche Rahmenbedingungen und unmittelbare Voraussetzungen schafft, mit denen sich diese Handlungen, Tätigkeiten und Arbeiten definieren oder rechtfertigen; daraus ergibt sich zwangsläufig:

- ihre Zielgerichtetheit, ihre selbstverstandene Gerichtetheit auf ein Erkenntnisziel oder produktives Ziel, auf ein Ergebnis hin, das sich seinerseits aus ebenjenem systematischen Zusammenhang ableitet oder rechtfertigt; dies bringt als Voraussetzung mit sich:

- ihre methodisch bewußte, kriteriengeleitete Vorgehensweise, die ihrerseits natürlich eng mit dem Systembezug zusammenhängt und ohne ihn gar nicht möglich wäre; dies wiederum ermöglicht: 
- eine soziale Beachtung, Beobachtung, ja Kontrolle durch die Transparenz (die ja mit der methodischen Vorgehensweise notwendig gegeben sein muß) bei den Ablaufstrukturen der Handlungen, Tätigkeiten, Arbeiten "im Fach". Hier schafft die Transparenz die Erkennbarkeit und Wiedererkennbarkeit, somit die Nachvollziehbarkeit (in den Wissenschaften, aber auch in den Technologien und Handwerken: die Nachprüfbarkeit, Verifikation) von Strukturen des Handelns, ihre Wertigkeit als Strukturen einer systematisch organisierten, übergeordneten Ganzheit; dies bringt dann mit sich:

- ihre Erfaßbarkeit in einem Regel- oder Anweisungswerk; und dies schafft wiederum die Voraussetzung für ein weiteres Konstitutivum der Fachlichkeit in Handlungen, Tätigkeiten, Arbeiten:

- ihre Lehrbarkeit, und damit als permanenter Fortschritt: ihre Verbesserung oder, neutral formuliert: ihre Modifizierbarkeit durch kritische (und das besagt wieder - s.o.! -: kriterienbestimmte ${ }^{30}$ ) Weiterentwicklung.

Diese Gemeinschaft von Kriterien der fachlichen Qualität des Handelns und Erkennens bedingt sich mit Ansprüchen an die fachliche Qualifikation der Handelnden in Theorie und Praxis, nämlich auf 31

- die Fähigkeit zum systematischen Erfassen sachlicher Zusammenhänge;

- speziell (durch Ausbildung, Lehre, Studium) erworbene Kenntnisse;

- Fertigkeiten (in Arbeitsprozessen, spezifischen Handlungsabläufen, Umgangs- und Kommunikationsgewohnheiten);

- (Erfahrungs- und Lern-) Wissen (zu einem Sachgebiet bzw. Handlungszusammenhang).

Diese Merkmale des fachlichen Handelns, fachbezogenen Tätigseins, Berufausübens, produktiven Arbeitens schlagen sich nicht nur in der tagtäglichen Mühe, in steten offenen oder versteckten Eignungsprüfungen und in permanenten Bewährungen nieder; sie sind als dominante Merkmale fachlichen Anspruchs auch systematisch in den Einzelsprachen vorhanden, was wiederum ihre dominante Funktion für die sozialen, psychischen und kognitiven Komponenten des Fachlichen in unserer Welt bestätigt. Allerdings bieten die Einzelsprachen hierzu einen verschieden komplexen Widerschein, speziell im begrifflichterminologischen Zugriff: 
So zeigt sich schon bei den Bezeichnungen der Fächer und Fachgebiete selbst, daß das Deutsche eine variantenreiche Palette an morphologischen oder lexikalischen Formen zur Verfügung hat, während die romanischen Sprachen hier andere, meist semantische Möglichkeiten (so die Polysemie, dann notwendigerweise mit hoher Kontextabhängigkeit) nutzen: ${ }^{32}$

So ist z.B. (aus einer Fülle von einschlägigen Belegen zu den Einzelsprachen) franz. journalisme im Deutschen 'Zeitungswesen', 'Zeitungswissenschaft', 'Journalismus' und 'Journalistik'; oder franz. comptabilité im Deutschen 'Rechnungs-/Kassenwesen', 'Rechnungs/Buchführung', 'Buchhaltung', 'Kontorwissenschaft', 'Kalkulatur'; oder das italienische cinematografia ist im Deutschen 'Filmkunst', 'Filmtechnik' und 'Filmwesen'; oder ital. ragioneria wird im Deutschen wiedergegeben mit 'Rechnungswesen', Buchhaltung', 'Buch-/ Rechnungsführung' und auch 'Verwaltungslehre';

oder span. genética entspricht im Deutschen 'Erblehre', 'Erbforschung', 'Vererbungswissenschaft' sowie 'Genetik'; oder span. dasonomía bedeutet im Deutschen 'Forstwirtschaft', 'Forstwissenschaft' und 'Forstwesen'.

Vergleichbare zielsprachige Varianten der Fachlichkeits-Wiedergabe auch im Englischen: Engl. jurisprudence ist im Deutschen neben 'Jurisprudenz' auch 'Rechtswissenschaft', 'Rechtskunde', 'Rechtsgelehrsamkeit', 'Rechtssystem'; oder engl. forestry bedeutet im Deutschen gleichermaßen 'Forstkultur', 'Forstwirtschaft', 'Forstwesen', 'Forstwissenschaft'.

Auch hat das Deutsche - wie auch die skandinavischen Sprachen mit dem einen Ausdruck 'Fach' offenbar ein begriffliches Kondensat, dem die anderen, hier: romanischen Sprachen kein ebenso dichtes Äquivalent entgegenzusetzen haben; sie drücken den Begriff 'Fach' z.B. bei 'Fach-abschluß', 'Fach-arbeit', 'Fach-geschäft', 'Fach-gespräch', 'Fach-mann', 'Fach-presse', 'Fach-wort' usw. - mit verschiedenen Lexemen (meist Adjektiven) eines kleinen Wortfeldes aus, so das Französische je nach Fall mit einem von mindestens sechs (allerdings nicht ganz wahlfrei) verfügbaren (unter ihnen spécial, professionnel, expert, technique),

das Spanische ebenso (z. B. técnico, especial, profesional, competente), das Italienische mit wesentlich mehr (darunter specializzato, tecnico, esperto, qualificato); 
im Englischen, zum Vergleich, gibt es mindestens sechs Lexeme, die die fachliche Qualität wiedergeben (special, expert, technical, professional, trained, skilled $\mathrm{u}$. a.). ${ }^{33}$

Analysen und Ergebnisse wie diese sind wichtig, weil sie den Blick auf kulturspezifische Sichtweisen, gesellschaftliche Relevanzsetzungen und sprachsystematische Handhabungen eines Begriffs von 'Fachlichkeit' öffnen:

\subsection{Kontroverse, Brisanz, Schwere, Regelung}

Fachlichkeit und fachsprachliche Repräsentanz sind begriffliche Schlüssel für die moderne Welt und durchziehen weite Bereiche des gesellschaftlichen und, als dessen Teil: auch des individuellen Lebens. Sie wirken als tragende Begriffe des öffentlichen (und privaten) Sprachgebrauchs auf die Einstellungen der Menschen zurück:

Sei es als kontroverse Begriffe, wie sie Georg Stötzel und Martin Wengeler (in Zusammenarbeit mit weiteren) zusammengetragen und in einer ausgezeichneten Publikation vorgestellt haben (Stötzel / Wengeler 1995), wo gerade das Thema 'Umwelt' prototypisch für "Fachsprache und Expertentum in der öffentlichen Diskussion" behandelt wird (Jung 1995 dort) und sich dabei als Teil durchaus benachbarter Herausforderungen wie terminologische Fragen in der Rüstungs-Diskussion (Kap. $4^{34}$ ), in der Bildungspolitik (Kap. $5^{35}$ ), bei der Anglophonie (Kap. $7^{36}$ ) durch Technik, Medien, Handel und internationalen Verkehr, oder auch bei der gesellschaftlichen Diskussion sexualethischer Fragen (Kap. 15 ${ }^{37}$ ) herausstellt.

Oder sei diese Einwirkung auf die Mitmenschen und Rückbindung an ihre Einstellung ausgeprägt als Herausforderung und Provokation, wie es Gerhard Strauß, Ulrike Haß und Gisela Harras mit ihrem "Lexikon zum öffentlichen Sprachgebrauch" als "brisante Wörter" fassen (Strauß / Haß / Harras 1989). Dort sind die Handlungsbereiche des modernen Menschen (aus der zweiten Hälfte der achtziger Jahre) umrissen mit "Politik und Ideologie", "Umwelt", und "Kultur und Bildung".

Oder sei die Einwirkung des Fachlichen zu begreifen im Sinne der sogenannten "schweren Wörter", engl. hard words, die schon vor Jahren, 1985, Gerhard Strauß und Gisela Zifonun als Herausforderungen spezifischer öffentlicher Erläuterungsstrategien und Klarheits- 
konzepte verstanden und dementsprechend in einer eigenen Lexikologie untersuchten. 38

Oder sei, als schließlich vierter Aspekt, diese Einwirkung im Sinne einer registrierenden Aufmerksamkeit und einer steuernden Reaktion darauf zu verstehen, indem nämlich über Sprachnormen, über Normen für den öffentlichen Sprachgebrauch nachgedacht wird und insbesondere die sprachliche Gestaltung fachlicher Themen in den Medien (Presse, Rundfunk, Fernsehen) kritisiert wird sowie die Fachsprachen des Rechts und der Verwaltung geprüft und zur Reformierung empfohlen werden. ${ }^{39}$

Fachlichkeit als mentalitätsgeschichtlich verankerte Ordnungsgröße der modernen Gesellschaften und Einschätzungsgröße ihrer Menschen, eingespannt, wie gesagt, in die dynamischen Bedingungen der Kontroverse, der Brisanz, der kommunikativen Schwere, der Regelung oder sogar Norm, darf in dieser durchgreifenden Komplexität den Anspruch erheben, heute die Schlüsselstellung innezuhaben und somit die soziale Führungsgröße zu sein. Die Fachlichkeit ist in der Welt, und sie beherrscht deren Menschen. Sie zeigt sich in den Wissenschaften, in den Technologien, in den verschiedenen Berufen, in den öffentlichen Institutionen, und auch im Alltag, dort in der Werbung, im Konsum, im Verkehr mit Behörden und Verwaltung, bei der Konsultation von Ärzten, Versicherungen usw., sie zeigt sich weiterhin im Haushalt bei der vielfältigen Organisation und Ausübung spezialisierter Tätigkeiten sowie differenzierter Verpflichtungen und komplexer Verantwortungsbereiche, und sie zeigt sich natürlich auch in der Freizeit bei den oft sehr speziellen, fachgebundenen Betätigungen im Rahmen von Hobbys; usw. usw.

Die Frage der siebziger Jahre, wo denn das Fachliche im gesellschaftlichen Umgang stecke - wenn das überhaupt als Frage auftauchte, da man sich ja sowieso an die in ihrer Fachlichkeit evidenten Fächer mit hohem Prestige hielt: Chemie, Physik, Mathematik, Medizin, Technik, Handwerke - diese Frage stellt sich heute, in der Dekade vor dem Jahr 2000, ganz anders, nämlich: wo denn das Fachliche nicht steckt, oder anders formuliert: wo es denn überhaupt etwas Nicht-Fachliches im organisierten, zielgerichteten Ablauf des Lebens gibt. 


\subsection{Fachlichkeit durch Fachsprachlichkeit}

$\mathrm{Da}$ unsere Welt eine fachliche, unser Handeln in ihr ein fachliches Handeln ist, läßt sich nicht einfach aus den Gegenständen, Sachverhalten und Handlungszusammenhängen als solchen ableiten. Einem Apfel ist genausowenig oder genausoviel an Fachlichkeit eigen - als natürlicher Eigenschaft - wie einem Fernsehturm, einem Automotor oder einer Blinddarmoperation. Daß wir dennoch fachliche Unterschiede sehen zwischen einem Apfel und einem Apfelkuchen, zwischen einem Klotz Eisen und einem Motorblock, zwischen dem Ausnehmen einer Forelle und der Herztransplantation bei einem Patienten ist dabei völlig unbestritten, weil evident - nur: woher weiß ich von diesen Unterschieden? Woher kann ich nach den schon genannten Merkmalen der Fachlichkeit - spezielle Kenntnisse, Fähigkeit systematischen Erfassens, Fertigkeiten, Lernwissen - diese Unterschiede einschätzen?

Wir können dies, weil wir über die Welt kommunizieren. Mit unserem Kommunizieren schaffen wir die Fachlichkeit der Welt. Ich kann über den besagten Apfel als Genießer, Hungriger, Obstfreund, Vegetarier, Biobauer, Marktkäufer, Chemiker, Biologe, Umweltschüzer, Theologe, Lehrer, EG-Kommissar, Mediziner reden - erst durch mein Sprechen über ihn wird klar, wie er von mir gesehen wird, welche fachliche Sichtweise ich als Sprecher habe. Der Apfel selbst ist kein fachlicher Gegenstand, er wird dazu gemacht durch die Sichtweise, in der ich über ihn oder mit Hilfe von ihm Aussagen mache. ${ }^{40}$ Und dementsprechend folgt der Hörer meiner sprachlich mitgeteilten Sicht auf den Gegenstand und behält diese in seinem Gedächtnis: er hat, wenn ihm noch nicht bekannt, nun einen fachlichen Aspekt hinzugelernt und kann diesen später seinerseits, indem er auf jene Vorgängertexte und Lernsituationen (für sich) rekurriert, verwenden. Dieser Weg des Lernens und der Speicherung im individuellen wie im kollektiven Gedächtnis ist es, der den dann aufgerufenen Gegenständen (wie einer Landkarte) oder Sachverhalten (wie dem Funktionieren eines Verbrennungsmotors) oder Handlungszusammenhängen (wie einer Herztransplantation) eine im vorhinein schon bekannte fachliche Qualität zubilligen läßt. Aber prinzipiell ist dies nur dadurch möglich, daß zuvor darüber fachlich kommuniziert wurde (in Vorgängertexten) und Lernen, Lehren, Erfahren und Behalten das fachliche Merkmal des Wissens und der Fertigkeit aufgebaut haben (als Memorierungsangebote). 
Es ist dann natürlich auch wieder die sprachliche Fassung, die Wahl der sprachlichen, dann selbstverständlich auch der fachsprachlichen Mittel, bis hin zu der Art der Vertextung und Entscheidung über die Textsorte, mit deren Hilfe diese Optik kundgetan wird und womit die Rezeption des mitgeteilten Inhalts als kaum, als weniger, als mehr, als voll fachlich gesteuert wird: So können wir das Märchen vom Rotkäppchen als fachbezogen praktisch kein Engagement fordernde Geschichte formulieren ("Es war einmal eine kleine süße Dirne, die hatte jedermann lieb, der sie nur ansah, [...]") oder, ganz fachsprachlich (institutionensprachlich) gehalten, als Amtsfall, was in der Parodie von Thaddäus Troll dann lautet: "Im Kinderanfall unserer Stadtgemeinde ist eine hierorts wohnhafte, noch unbeschulte Minderjährige aktenkundig, welche durch ihre unübliche Kopfbekleidung gewohnheitsrechtlich Rotkäppchen genannt zu werden pflegt". ${ }^{41}$ Wir lesen Goethes Tragödie "Faust" als literarisches Werk, können sie aber auch als Ansammlung von Tatkomplexen verstehen, die juristischer Prüfung unterzogen werden müssen (Gotteslästerung, Hausfriedensbruch, Verführung Minderjähriger, gemeinschaftlicher Mord, u. a.), was - auch als fachlicher Spaß gerade im Extremen ${ }^{42}$ - die Möglichkeiten fachlicher Optik durch fachbezogene Kommunikation offenbart: Hier wird Fachlichkeit konstituiert, geschaffen durch (hier: juristische) Fachkommunikation mit Termini und typischen fachsprachlichen Strukturen der juristischen Texte sowie eindeutigen juristischen Textsorten-Merkmalen (so Tatermittlung, Strafanzeige, Vernehmungsprotokoll, gutachterliche Erwägungen, Anklageschrift). Umgekehrt können wir ein fachliches Anliegen wie Kochen und Backen statt entsprechend in fachsprachlichen Anweisungstexten zu formulieren natürlich auch, mit der eingesetzten sprachlichen Signalgebung, als einen literarischen Genuß anbieten ${ }^{43}$; oder einen Stadtführer mit einer Fülle fachlicher Intentionen und Informationen als ein Literaturkompendium gestalten ${ }^{44}$ oder die Geschichte der Philosophie in Form eines Romans vermitteln ${ }^{45}$ oder astronomische Probleme, wie in den Dialogen, Unterhaltungen oder Gesprächen der Renaissance und der Aufklärungszeit, hier insbesondere in Frankreich, traktiert, in literarisch wohlgefälliger und bei aller Fachlichkeit verständlich lesbarer Weise lehrend entfalten ${ }^{46}$. Schließlich sei auch nicht das Prinzip des Ineinandergreifens vergessen, indem Literatur fachliche Inhalte behandelt oder widerspiegelt; hier sei speziell nur an die Grundsätze des literarischen Realismus erinnert. ${ }^{47}$ 
Diese Problemstellung zielt bereits auf die innersprachlichen Kontakte (s. 2.5.).

Wenn Fachlichkeit, wie gesagt, als ein soziale Führungsgröße unserer Zeit anzusehen ist, dann muß das Kommunikationsmittel, das diese Fachlichkeit erst schafft, auch den gesellschaftlichen Mitteilungsbedürfnissen und Sichtweisen entsprechen. Und die wechseln ständig, verändern sich. Wir brauchen nur an Reizbegriffe aus der (Umwelt-) Technologie wie 'Kernkraftwerk', 'Waldsterben', 'Tempolimit', 'Recycling', 'Ozonloch' oder aus der gesellschaftsethischen Diskussion wie 'Abtreibung', 'Genmanipulation' oder 'Asyl' und die Argumente dazu am Stammtisch, beim Familienmittagessen, abends in der Kollegenrunde, bei der öffentlichen Anhörung, im Fernsehen bei Expertenbefragungen, in Interviews der Jugend, der Betroffenen oder der sogenannten Sachverständigen erinnern, um zu erkennen, wie Fachkommunikation zum selben Gegenstand, Sachverhalt oder Handlungszusammenhang unterschiedlich ausfällt. Das Modell der fachlichen Konstellationen im Kommunikationsproze $\aleph^{48}$ -

- der Fachmann eines Faches spricht mit dem Fachmann seines Faches,

- der Fachmann eines Faches spricht mit dem Fachmann eines anderen Faches,

- der Fachmann eines Faches wendet sich an den fachlich interessierten Laien -

kann deshalb nur eine grobe Orientierung bieten. Und dementsprechend ist auch, was die Text-Intention betrifft, die inzwischen etablierte Dreier-Einteilung 49 in

- 'innerfachliche' oder 'fachinterne' (d.h. also innerhalb der jeweiligen Fächergrenzen),

- 'interfachliche' (d.h. zwischen den einzelnen Fächern, also die Grenzen der einzelnen Fächer überschreitend, und dies kooperativ wie auch kontrastiv) und

- 'fachexterne' Kommunikation' (d.h. fächerüberschreitend, sich an interessierte Laien mit fachlichen Inhalten in einer entsprechend aufbereiteten Auswahl und sprachlichen Darstellungsweise wendend) nur in ihrer Zuordnungsleistung hilfreich, ansonsten aber als Beschreibungsform ungeeignet. Und auch die bekannten vertikalen Schichtenmodelle, so das mit Recht herausgestellte von Lothar Hoffmann ${ }^{50}$, nehmen lediglich einen annähernden heuristischen Wert für sich in 
Anspruch, was natürlich bei den ersten Schritten text- und kommunikationsbezogener Analysen zunächst als ein unverzichtbares methodisches Mittel der Ortung und der Reduktion dienen kann.

Das Problem derartiger Versuche steckt darin, daß sie die Wirklichkeit in feste Kategorien modellieren, wo doch die lebendige Dynamik der Fachkommunikation in den Texten, in den sprachlichen Äußerungen zu suchen wäre. In den Texten ist über die Intensität der Fachlichkeit und über den Anteil der sie darstellenden Fachsprachlichkeit entschieden, und nur sie, die Texte zwischen Sender und Empfänger, signalisieren, ob und wie der Autor eine fachliche Sehweise - und dann natürlich: welche fachliche Sicht er gewählt hat und dem Hörer oder Leser anbietet.

\subsection{Graduelle Stufung von Fach(sprach)lichkeit: Skala}

So ist es sinnvoll, die Dynamik der Texte auch für eine Auffassung von 'Fachsprache' zu nutzen, die sich abkehrt von einem Zuordnungsmodell, in dem auf der einen Seite die Fachsprache oder die Fachsprachlichkeit steht, und auf der anderen Seite deren Negation, die Nicht-Fachsprache, üblicherweise genannt die Gemeinsprache. Ich setze mich - ich glaube, mit guten Gründen ${ }^{51}$ - dafür ein, diese meines Erachtens künstliche und in den konkreten Einzelfällen überhaupt nicht leistungsfähige Modell-Antipode von 'Gemeinsprache' hier und 'Fachsprache(n)' dort aufzulösen, also keine Koexistenzform von 'Gemeinsprache' einerseits und 'Fachsprache(n)' andererseits anzunehmen, und dann konsequenterweise auf den Begriff 'Gemeinsprache' zu verzichten; und zwar dies zugunsten der Vorstellung einer graduellen Stufung von 'Fachsprachlichkeit'. Dem steht eine ebenfalls graduelle Stufung von 'Fachlichkeit' als der über die Texte zugewiesenen (außersprachlichen) Qualität von Gegenständen, Sachverhalten und Handlungszusammenhängen zur Seite. Die Fachsprachlichkeit eines Textes, also dessen Qualität z. B. als Fachtext oder als "nicht ganz" Fachtext oder als "nahezu kein" Fachtext (was wir oft schon intuitiv erfassen), wird über die sprachlichen Signale aller Sprachebenen geleistet (Phoneme, Grapheme, Morpheme, Lexeme, insbesondere natürlich Termini, syntaktische Spezifika, Textspezifika wie Thema-Rhema-Verteilungen, Makrostrukturen, Kohärenzen, Isotopien und -ketten, TextsortenMerkmale, situative, also textpragmatische Besonderheiten, bis hin zu semiotischen Ausweisen wie Text-Bild-Beziehungen). Ihr Vorhanden- 
sein (Distribution, Frequenz, Rekurrenz) prägt den fachsprachlichen Charakter der Texte. Eine graduelle Stufung von Fachsprachlichkeit als Textqualität ${ }^{52}$ mißt sich also an der Skala von '(extrem) merkmalarm' bis hin zu '(extrem) merkmalreich'.

Mit einer solchen Lösung haben wir die ehemaligen Aporien vertrieben, weil hier am Anfang der Text mit seinen Signalen, eben nicht ein antipodisches Modell, steht; und dieser Ansatz genau scheint richtig und angemessen, weil es eben die Texte, nur die Texte sind, die in der Fachkommunikation die Gesellschaft zusammenbinden und so die Fachlichkeit und die Fachsprachen zu einer sozialen Führungsgröße haben anwachsen lassen.

Und indem auf diese Weise die Gemeinsprache als angebliche Koexistenzform von Fachsprache konzeptionell aufgelöst ist und der Begriff 'Fachsprache' den Platz in einem graduellen Verständnis hält, konturieren sich dann auch die Existenzformen der Fachsprachlichkeit (2.5.): nämlich die Fachsprache als Wissenschaftssprache, als Institutionensprache, als Techniksprache, zu denen - aus frühesten Zeiten tradiert und meistens auf dialektalem Substrat gesprochen - natürlich auch die handwerklichen Fachsprachen zählen, und schließlich die Fachsprache als Gruppensprache (oder auch bezeichnet als Sondersprache). 53

\subsection{Innersprachliche Kontakte}

Im Rahmen der inneren Mehrsprachigkeit einer Einzelsprache (wie sie gerade angesprochen worden ist) gibt es ständig innersprachlichen Kontakt, der seinerseits eine Vernetzung vielfältiger fachsprachlicher Kommunikation schafft und so auch die Funktion einer sozialen Führungsgröße stützt.

Der Ort der Kontakte sind natürlich wiederum die Texte, und zwar insbesondere jene, die in Kommunikationssituationen auftreten, die nicht in allen Hinsichten fachlich sind. Ihr Auftreten auf allen Sprachbeschreibungsebenen birgt neue kommunikative Möglichkeiten, gerade auch für die Kommunikationsbeziehungen zwischen unterschiedlichen Fächern. Von besonderem Reiz ist dabei die Beobachtung, daß in Kommunikationsbereichen, die insgesamt nicht als fachlich eingeschätzt werden, dennoch fachsprachliche Phänomene auftreten. Besonders die Alltagskommunikation, hier auffallend die Werbung als der stark 
pragmatische, sowie die Schöne Literatur als der eher ästhetisch bestimmte Kommunikationsbereich bieten sich hier als ergiebige Untersuchungsfelder an. An interessanten und auch interdisziplinär (so z.B. im ersten Fall in die Psychologie, im zweiten Fall in die Literaturwissenschaft) ausgreifenden Problemen empfehlen sich hier Fragen zu den eingestreuten Sprachmitteln, die Gründe für ihre Wahl, natürlich auch die Mischungsverhältnisse und ihre Ausformungen je nach Textsorten, dann die inhaltlich bevorzugten Fachgebiete, die Wirkung der fachsprachlichen Phänomene auf das jeweilige Textganze, die Reaktion der Hörenden und Lesenden auf die fachsprachlichen Einstreuungen, was wiederum hineinführt in eine Texte- und darüber hinaus Sprachkritik.

$\mathrm{Zu}$ diesen Mechanismen, Funktionen und Wirkungen fachsprachlicher Phänomene in alltagskommunikativen oder literarischen Texten fehlt es allerdings noch an gezielter Forschung, erst recht in breitem Zugriff. Und auch die Gegenrichtung, nämlich die Auswirkung von sogenannten gemeinsprachlichen - ich möchte eher sagen: fachsprachlich äußerst merkmalreduzierten - Phänomenen im und auf den fachsprachlichen Text sowie auf die Darlegung eines fachlichen Inhalts, findet bislang noch erst bei recht wenigen gebührendes Interesse.

2.5.1. Dabei liegt gerade hier eine der großen Chancen für die Kommunikation in der arbeitsteiligen Gesellschaft auf die Frage: Wie läßt sich das fachlich merkmalreiche Anliegen (z. B. gentechnologische Neuentwicklungen) in fachsprachlich deutlich merkmalärmerer Textfassung mitteilen? Oder anders formuliert: Wie läßt sich Fachinformation laiengerecht, also dem Nichtfachmann verständlich, aufbereiten?

Quelle und Ziel dieser Fragestellung sind nicht linguistisch, erst recht nicht fachsprachenlinguistisch motiviert, sondern vielmehr genuin sozial geprägt:

Mit der vorwärtsschreitenden Differenzierung der Arbeitsgebiete, Wissensbereiche und Fächer spätestens ab dem 19. Jahrhundert haben wir nämlich inzwischen, im 20. Jahrhundert, und hier insbesondere in der zweiten Hälfte, einen Zustand erreicht, in dem die Fächer ihre im Indogermanischen noch handwerklich angelegte Arbeitsfunktion des Einrammens, Verzäunens, dabei dann des Eingrenzens nach innen und Ausgrenzens nach außen deutlich wiederaufleben lassen: Das Spezia- 
listentum ist heutzutage hochgeschätzt und zur Lösung punktueller Herausforderungen gefragt, aber schon weiß der Spezialist eines Gebietes im Nachbargebiet nicht mehr ausreichend Bescheid, schon wacht der dortige Spezialist über die privilegierende Wahrung seiner Kenntnisse und subtilen Einblicke.

Das neue prestigeträchtige Leitbild des Expertentums und Spezialistentums hat die modernen Gesellschaften im Fachlichen durch die Fächer zersplittert; die Gesellschaft hat sich in der fachlichen Partikularisierung entfremdet; der ehemals gesellschaftstragende Begriff der breiten Allgemeinbildung, wie er sich in dem alten Gedanken der universitas verdichtet, ist in Öffentlichkeit und Wissenschaft obsolet geworden. Die Ausbildungsgänge und Lehrziele in unseren Schulen und höheren Anstalten beweisen diese Haltung schmerzlich.

Folglich fehlt inzwischen eine breite Basis, auf der es möglich wäre, miteinander die neben den fachlichen Segnungen auch allfälligen fachlichen Probleme, die die Gesellschaft bedrängen und durchaus auch bedrohen, zu diskutieren und im gesellschaftlichen Konsens zu lösen. Der Wille zur mitverantwortlichen Gestaltung setzt allerdings die Möglichkeit voraus, informiert zu sein, Bescheid zu wissen, eben Fachkenntnisse im Rahmen der zwar fachlich ungeschulten, doch motivierten Aufmerksamkeit, also des engagierten Interesses erwerben zu können. Wenn hier aber eine Sperre liegt, weil sich Kommunikationslosigkeit breitmacht, die in der Unfähigkeit gründet, sich über die fachlichen Zäune und Mauern hinweg zu verständigen, dann ist dies ein Leiden der modernen Gesellschaft, das die Verursacher beseitigen müssen. Sie haben die Verpflichtung zur Verständigung: eben mit Verständlichkeit der Darstellung ein annäherungsweises Verstehen des fachlichen Inhalts $\mathrm{zu}$ erreichen und so ein tieferes Verständnis für Zusammenhänge zu schaffen; dies wirkt sich dann prägend auf Einschätzungen, Meinungen und Urteile aus und verbessert so das soziale Klima deutlich zu Kooperation und Verantwortung hin.

Hierin verdeutlicht sich das untrennbare Bedingungsgefüge zwischen den drei Faktoren 'Sprache' (Fachsprache), 'Sachwelt' und 'Gesellschaft' (gesellschaftlicher Handlungswelt). Gerade in dieser allumfassenden Geltung wächst der Begriff der 'Verständlichkeit' zu einer Herausforderung an Fachleute, Wissenschaftler, Institutionen, Medien, Ausbildungsstätten (schulische Einrichtungen), - und an jedes einzelne Mitglied der Gesellschaft, an sein Interesse, seine Initiativen, 
seine wache, kritische Bewußtheit für transparente Information, für verständliche Darlegung fachbezogener bzw. fachlicher Inhalte. ${ }^{54}$

Da diese Prozesse mit Kommunikation zu tun haben, ja nur so zu einem effizienten Ziel führen können, ist auch die Fachsprachenforschung gefordert. Bislang hat sie sich hier wenig engagiert und die Aktivitäten anderer, benachbarter Disziplinen leider nur beiläufig zur Kenntnis genommen (s. 2.5.2. und 2.5.3.):

2.5.2. So hat die sogen. Lesbarkeitsforschung schon seit Mitte der dreißiger Jahre den Blick gelenkt auf die mögliche Optimierung von Texten durch stilistische und auch drucktechnische Eingriffe ${ }^{55}$. Mit ihren "Lesbarkeitsformeln" bemühte sie sich, über quantifizierte Eigenschaften des Textes (so die durchschnittliche Wortlänge, Anzahl der Wörter pro Satz oder Anzahl der Silben pro hundert Wörtern) die Texterstellung (insbesondere in Schulbüchern) bewußt zu machen und die Lesbarkeit - die ihrerseits ja durchaus noch nicht Verständlichkeit ist - zu gewährleisten.

Mit der Textlinguistik und den rezeptionsorientierten Modellen zur Textverarbeitung kamen in den siebziger, Anfang der achtziger Jahre dann lern-, instruktions- und kognitionspsychologische Aspekte des kognitiven Konstruktivismus hinzu 56 , die einen ganzheitlichen, nämlich die Textproduktion wie auch die Textrezeption umfassenden Begriff von 'Verständlichkeit' ermöglichten. Hierdurch war der Leser nicht mehr abgestempelt zu einem bloßen Empfänger der Textinformation (bottom-up-Prozeß), der sich für seine Verstehensleistungen an die sprachlichen Einheiten halten muß; vielmehr definiert er sich als aktiv den Verstehensprozeß mitgestaltend, indem er die Textinformationen mit seinem Vorwissen, seiner Welterfahrung, seinen Kenntnissen zum Thema ergänzt und seine Lesekompetenzen mit einbringt (Kombination von bottom-up und top-down-Prozessen).

Schwerverständlichkeit, überhaupt die Textqualität 'Verständlichkeit', ist grundsätzlich relational zu verstehen, als eine prozessuale Beziehung zwischen fünf Komponenten: nämlich zwischen Autor, Text, sachlich angemessenem Bezug (fachlicher Richtigkeit), Textrezipient und Kommunikationssituation mit ihren sozialen und kulturellen Bedingungen. Absolutierende Wertungen lassen sich da wohl kaum treffen. Gerade deshalb ist es so schwierig, Techniken, vielleicht sogar Strategien des Besser-Schreibens, also der Textoptimierung zu ent- 
wickeln und $\mathrm{zu}$ empfehlen; erst recht dürfte es problematisch sein, Regeln dazu - zumal mit generalisierendem Duktus - aufzustellen, zumindest noch zum jetzigen Forschungszeitpunkt. Ein übliches Verfahren bei der kritischen Sichtung des Gestaltens verständlicher Fachtexte - hier vorzugsweise von technischen Texten - ist die textimmanente Prüfung des Textstils, im Sinne einer Wissenschaftssprachstilistik $^{57}$.

So ist das recht bekannt gewordene empirisch-induktive Verständlichkeitskonzept der (damaligen) Hamburger Gruppe (allesamt übrigens Psychologen) Inghard Langer, Friedemann Schulz von Thun und Reinhard Tausch ${ }^{58}$ von 1981 stark an Kriterien aus der traditionellen wertenden Literaturstilistik orientiert: nämlich mit den vier Hauptgesichtspunkten 'Einfachheit', 'Gliederung / Ordnung', 'Kürze / Prägnanz', 'Anregende Zusätze' (was die Rhetorik unter ornatus faßt). Die gängige Methode der kritischen Gegenüberstellung ("Nicht so: ..." mit dem inkriminierten Text; "Sondern so: ..." mit dem purifizierten oder optimierten Textvorschlag) $)^{59}$, die mit diesem Transferieren stark an Vorgehensweisen der Übersetzungspraxis (Relation zwischen Ausgangstext und Zieltext) erinnert (Biere 1989: 213-244), beachtet weder die Vorkenntnisse und sozialen Merkmale des Leseradressaten noch die spezifischen Konventionen und Charakteristika der verschiedenen fachlichen Textsorten, und sie bemißt den Erfolg gern mit prozentualen Umfangs-Einsparungen (als ob dies ein grundsätzlich geltender, maßgeblicher Gesichtspunkt für Verständlichkeit sein könnte!).

Es sollen aber auch nicht jene Bemühungen im Umfeld einer sprachkritischen Haltung zu der Auseinandersetzung zwischen Deutsch und dem Konkurrenten Englisch als Wissenschaftssprachen im deutschsprachigen Raum unerwähnt sein: Hierzu hatte seinerzeit, 1985, das 25. Konstanzer Literaturgespräch deutliche Zeichen gesetzt mit einer Fülle provokanter wissenschafts- und forschungsbezogener sowie gesellschaftsorientierter Fragen, eher Anfragen, speziell auch zum "guten Deutsch". ${ }^{60}$ Als Leitpunkte und Anforderungen für ein gutes, transparentes, verständliches, stilistisch zufriedenstellendes Vertexten finden sich Qualitäten wie (Gauger 1986) 'dienendes Sprechen', 'Faßlichkeit' (was als sachlich praktischer Begriff "dem eher ins Ästhetische hinüberspielenden der 'Klarheit", vorgezogen werde ${ }^{61}$ ), sodann sprachliche 'Anmut', und schließlich 'Eigenprägung' (als Be- 
griff für individuellen Stil in wissenschaftlichen Texten); oder es finden sich in ihrer Art schon länger bekannte Stilgrundsätze, wie sie Oksaar (1986: 110) für die mündliche wie auch für die schriftliche Fach- und Wissenschaftssprache nochmals kondensiert: 'Klarheit / Eindeutigkeit', 'Genauigkeit / Vollständigkeit', 'gedankliche Ordnung / Übersichtlichkeit', 'Knappheit / straffe Bündigkeit', 'Schlichtheit / Mäßigkeit', 'Angemessenheit' (in Ton und Sache), 'Anschaulichkeit / Eingängigkeit'. 62

Und selbstverständlich dürfen die kulturhistorischen Aspekte dieser Herausforderung nicht vergessen werden. Hier finden sich bislang kaum Beachtungen, wenngleich Pörksen mit seinen beiden Bänden (1986; 1994) in hervorragender Weise verdeutlicht, daß und wie die aktuelle Diskussion aus der Tradition (Paracelsus, Lichtenberg, Leibniz, Linné, Goethe, Darwin, Jochmann, Nietzsche, Freud u.a.) Konzepte übernehmen und dabei selbst für ihre Kriterien Schärfe und Sicherheit für qualitative Beurteilungen gewinnen kann. Ähnlichen Ertrag (so zu Wolff, Pascal, Freud) vermittelt der aus einer interdisziplinären Arbeitsgruppe 'Wissenschaftssprache' an der Akademie der Wissenschaften zu Berlin 63 entstandene Band von Kretzenbacher / Weinrich [Hrsg.] (1995).

2.5.3. Aus dieser Tradition der Bemühungen (2.5.2.), Verständlichkeit als eine Mitteilungsqualität zwischen Fachleuten und Laien über verschiedene sprachliche Eingriffe und Techniken in den fachlichen oder fachbezogenen Texten zu sichern oder aber überhaupt erst herzustellen, ist seit Anfang der achtziger Jahre in Deutschland das sogen. Technical Writing, das 'Schreiben in der Technik' oder 'Technische Schreiben' oder, wohl noch angemessener, weil komplexer, die 'Technische Kommunikation' als eines der wichtigen Praxisfelder im Bereich der Fachkommunikation entstanden. Die unter diesem Etikett versammelten Bemühungen um optimierte Fachtexte streben eine Vermittlung zwischen Sachangemessenheit und Adressatenbezug an. ${ }^{64}$ Der weitgefächerte und anspruchsvolle Bedarf an einschlägiger Informationsbeschaffung $\mathrm{zu}$ den Produkten, zu den Entwicklern, Anwendern und Verbrauchern, weiter die Notwendigkeit der verschiedenartigen Formen und Konzeptionen von Dokumentation dazu, wie natürlich auch deren sensible Betreuung je nach Adressaten, Informationsbedarf und Veränderungen bei der Produktentwicklung haben 
inzwischen ein qualifiziertes neues Berufsbild herausschälen lassen: nämlich den Technischen Redakteur / die Technische Redakteurin. Das Anspruchsprofil des Berufsbildes ${ }^{65}$ verlangt einschlägiges produktbezogenes Wissen, setzt eine ausgebaute rezipienten- (d.h. meist: verbraucher- oder weiterverarbeiter-) orientierte Sprachkompetenz und eine ausgebildete Formulierungssensibilität (Texterstellung, Textoptimierung) voraus, umfaßt außerdem juristische (man denke nur an die Gesetzgebung zur Produkt-, Material- und Informationshaftung!), betriebswirtschaftliche und organisationstechnische Kenntnisse und erwartet schließlich auch didaktische und ästhetisch-künstlerische (Bilder, Grafiken, Illustrationen! ${ }^{66}$ ) Fähigkeiten. Damit sind über die Belange der Praxis auch jene Bereiche - in interdisziplinärem Engagement und in Verbindung von Spezialisierung und auch generalistischer Ausrichtung - der modernen Fachsprachen aufgezeigt, auf die die Fachsprachenforschung, inzwischen eher zu verstehen als Fachkommunikationsforschung, eingehen und die sie mittragen muß.

Dabei erscheint der Ansatz von Bernd-Ulrich Biere (1989) eines aktiven, die Lehr-Lern-Situation antizipierenden und deshalb dialogisch konzipierten Verständlich-Machens ein sinnvoller Weg zur Textoptimierung zu sein. Er erscheint deshalb gangbar, weil er schon durch die Tradition beglaubigt ist:

Die französische Aufklärung ist die hohe Zeit der Popularisierung oder vulgarisation von Fachthemen (z. B. der Astronomie) für die interessierte Laienöffentlichkeit, durchgeführt von philosophe-écrivains, die die Philosophie als Sammelbecken fachlicher Aktivitäten verstanden und sich in einem eigentlich fachneutralen, wenngleich selbst durchaus fachlichen Genre, nämlich dem der Literatur, äußerten: So Blaise Pascal, der mit seiner Sprache zeigt, daß die Fachthemen der Religion literarisch umgesetzt werden können; oder René Descartes, der mit seinen Schriften beweist, daß die Fachprobleme der Philosophie als literaturfähig gelten dürfen; oder Bernard Le Bovier de Fontenelle, der die Literatur für die Naturwissenschaft, die Fachthematik für die Literatur öffnet. Wir erleben einen Stil der Balance zwischen ernsthafter Belehrung und verschönerndem, meist galantem Beiwerk "ni trop sèche [...] ni trop badine"67_, der zwischen instruire und divertir vermittelt und damit natürlich an die poetische Tradition, so bei Horaz, von docere et delectare, von utile et dulce anschließt. 
2.5.4. Das ist eigentlich in nur einer didaktischen Konstellation wirklich auszuschöpfen, nämlich im dialogischen Lernen. Und der Philosoph und Poet Bernard Le Bovier de Fontenelle (1657 - 1757) zeigt uns in dem Meisterwerk der vulgarisateurs, in seinem "Entretiens sur la Pluralité des Mondes” (1686) (übersetzt von dem Naturwissenschaftler Johann Elert Bode als 'Dialogen über die Mehrheit der Welten', Berlin 1780), daß diese dialogische Didaktik den Ansprüchen des interessierten Laien an eine Verständlichkeit der darstellenden Sprache auch tatsächlich gerecht wird: Denn indem der lernende Partner in das lehrende Gespräch und die fachlichen Inhalte als Fragender einbezogen wird, rückt er so aus dem Schatten des unmündig rezipierenden und den Entscheidungen des belehrenden Fachmanns ausgelieferten Laien nun in das Licht - wir sind ja in der Zeit der Aufklärung! - des mitdenkenden, aktiven, seine Vernunft einsetzenden und seinen Verstand kritisch mitgebrauchenden Partners im Fachgespräch.

Was wir in unserer vorwiegend monologischen Diskursform der Fachtexte und Wissenschaftsprosa daraus an jetzt umsetzbarer Anregung ableiten können, ist der hohe Stellenwert der partnerbezogenen, somit adressatengerichteten, also leserantizipierenden 'Erklärung'. Diese halte ich im Rahmen der Fachlichkeit und Fachsprachlichkeit als sozialer Führungsgröße für den wichtigsten, weil bewußt kommunikationssichernden Leitbegriff.

Der Leitbegriff 'Erklärung' bezieht sein Gewicht zum einen aus der Lexikographie, deren Anliegen und Aufgabe es stets war und ist, Wissensgefälle $\mathrm{zu}$ überbrücken durch Hilfen des Verstehens von Unverständlichem. Und dies eben bezogen auf sachorientierte oder auf sprachorientierte Informationslücken, worauf sich bekanntlich die beiden prinzipiellen Typen der Enzyklopädie einerseits - hier sind wir wieder bei den artes, speziell den Wissenschaften der freien Künste: egk'yklios paideía - und dem Wörterbuch andererseits beziehen.

Der Leitbegriff des 'Erklärens' leitet seine zentrale Stellung aber zum anderen auch ab aus den Strategien, mit denen inzwischen bis in die Zeitungstexte hinein die möglicherweise unverständlichen Informationen für den interessierten Laienleser aufbereitet werden: 68

Die erste Möglichkeit ist, einen auftauchenden Terminus sofort im Satzverlauf zu erklären, wobei metasprachliche Hilfen entsprechende Signale setzen: z. B. 'darunter versteht man', 'das bedeutet in der Fachwelt' 69 
Die zweite Möglichkeit ist das zwar eigenständige, aber in den Text integrierte Informationsangebot zu einem Terminus oder einem noch unbekannten Sachverhalt. Hierbei finden sich dann eigene Kästen oder Rubriken im Text, z. B. in einem Bericht über die französischen Atomversuche eigene Blöcke zum Stichwort 'unterirdische Atomzündung' und zu dem Fachwort 'Atoll'. Das ist ein verkappt dialogisches Informationsangebot an den Leser, der es nutzen kann, indem er diese eigenständigen quasi-lexikographischen Informationsblöcke liest und das neue Wissen dann in seinen weiteren Textleseprozeß einbringt. Diese Strategie, Verständlichkeit durch Erklärungsangebot zu sichern, findet sich auffällig in guten Tageszeitungen und in allen Printformen des Wissenschaftsjournalismus, insbesondere populärwissenschaftlichen Fachzeitschriften.

Die dritte Möglichkeit, im voraus vermutete Informationslücken und somit antizipierte Unverständlichkeiten eines Textes $\mathrm{zu}$ beheben, besteht darin, ein textbezogenes Glossar oder Register oder Verzeichnis anzufügen. Das ist dann schon ein deutliches lexikographisches Angebot, wenngleich spezifisch angebunden an den Informationsbedarf, wie er sich aus den semantischen Problemen des da konkret vorliegenden Textes ergibt. Auch dabei ist der Leser Souverän über seine Konsultationen. Wir finden diese manifeste dialogische Didaktik insbesondere als Anhang - "Glossar" - von Texten der Textsorte 'Sachbuch' sowie von der literarischen Variante der Textsorte 'Sachbuch', nämlich dem 'Historischen Roman'.70

Es sind also die verschieden komplexen und verschiedenartig eingesetzten Formen der Information "mit anderen Worten", also der Periund Paraphrase, meist metasprachlich angeschlossen (mit anderen Worten, das soll heißen, will sagen, anders formuliert usw.), um eben Zusatzsinn zu schaffen, indem das kommunikativ störende Neue durch bereits Bekanntes verstehbar wird; es sind somit die Arten der Auflösung von - in diesem Sinne: - 'Neologismen' in die Verstehbarkeit und Benutzbarkeit hinein ${ }^{71}$, der Umformulierung oder Übersetzung in einen anderen Code - oder mit Greimas (1970): der transcodage -, die die mehr oder weniger dialogische Rückbindung des Textautors an den von ihm antizipierten Rezipienten leisten und darin dann dem Text seinen Signalwert aufprägen: eben den, für einen Fachmann, für einen interessierten, wissenden Laien, für einen Anfänger usw. geschrieben 
oder gesprochen zu sein und darin die typischen ${ }^{72}$ Merkmale der fachlichen und fachexternen Textsorten zu vermitteln.

2.5.5. Das Sachbuch gehört zu den Textsorten, ja ist wohl jene Textsorte, die innerhalb meines hier gesteckten Rahmens der Fachlichkeit und Fachsprachlichkeit als sozialer Führungsgröße die auffallend dominante Funktion innehat und darin auch schon recht früh erkannt worden ist ${ }^{73}$. Der Sachbuch-Markt boomt, und dies gilt auch für die literarische Variante des Sachbuchs, nämlich den 'Historischen Roman'. Inzwischen, nach dem wohl allgemein als eines der ersten Sachbücher in Deutschland eingeschätzten Werk von C. W. Ceram, alias Kurt W. Marek, "Götter, Gräber und Gelehrte. Roman der Archäologie" (1949), in dem noch vorsichtige Überlegungen zur wissenschaftlichen, nämlich archäologischen Fachlichkeit und zur romanhaften Darstellungsweise das Vorwort bestimmen, ist jedes gesellschaftlich relevante, öffentlich inspizierte Fachgebiet über Sachbücher für das breite Lesepublikum erfaßt. Das Printmedium, dessen Leitmotiv 'Erklären' heißt, hat sich dabei, wie überhaupt der Wissenschaftsjournalismus (der insbesondere in den fachextern gerichteten, zwischen Fach und Alltag, zwischen Fachmann und interessierten Laien vermittelnden Zeitschriften gedeiht ${ }^{74}$ ), offensichtlich kulturenspezifisch entwickelt; so besitzen die romanischen Sprachen kein Übersetzungsäquivalent für 'Sachbuch' und begreifen es in Anlage und Funktion auch anders als die angloamerikanische Welt oder der deutschsprachige Buchmarkt und Käufer.

Eine gewisse Egalisierung der Rezeptionsgewohnheiten allerdings bringt die Medien-Konkurrenz mit sich: das Sachbuch als Printmedium gegenüber der mündlichen Wissenschaftssendung im Fernsehen. Auch hier, in der visuellen und auditiven wissenschaftlichen Breitenwirkung, geht es in erster Linie um Verstehen durch Verständlichkeit, um Verständlichkeit durch Erklären, um Erklären durch die geschickte Gemeinschaft von Sprache und außersprachlichen Mitteln (Bilder, Körpersprache, Geräusche).

2.5.6. Hier steckt - gerade auch, wenn sie sich kontrastiv, und dabei sogar interkulturell, begreift - ein gewaltiges Potential für die Fachsprachenforschung; sie kann dabei in herausragender und zugleich sehr 
verantwortungsvoller Weise ihre Brückenfunktion zwischen einerseits Sachgebiet bzw. Fach, andererseits Sprache bzw. Kommunikation, und schließlich Gesellschaft und Ausbildung, Kenntnisvermittlung, Sicherung von Verstehen wahrnehmen und verdeutlichen. Dieser Komplex läßt sich, wie ich 1988 vorgeschlagen habe, begrifflich besetzen, und zwar in Anbindung an alte Traditionen der Kultur des Erklärens, der Verständnissicherung, also der - mit Quintilian - Wahrung von Durchsichtigkeit und Verstehen der Rede durch interpretare, griech. hermenéuein ${ }^{75}$ : man kann ihn besetzen als 'Fachsprachen-Hermeneutik' oder, nicht so sehr Disziplin-Bezeichnung, vielmehr konkreter den Prozeß meinend, 'fachtextuelle' oder, hier komplexer sehend, 'fachkommunikative Hermeneutik'.

Der Begriff 'fachkommunikative Hermeneutik' zielt, das sollte evident geworden sein, auf

- antizipierendes Autor-Bewußtsein über sein Lesepublikum; sodann auf

- die Strategien im Text, die Textqualität der Verständlichkeit adressatengerecht zu verwirklichen: es sind dies

- implizit didaktische Strategien (wie z. B. die Wahl des dialogischen Entfaltens von Sachinformation) oder

- explizit didaktische Strategien (wie sprachliche und nichtsprachliche [Hilfs-]Mittel zum Erklären); schließlich auf

- die Leistung des Rezipienten, die Angebote der Verständlichkeitssicherung und somit eines ihm angemessenen Textverstehens $\mathrm{zu}$ nutzen, und zwar in aller Souveränität (ob er z. B. ein beigefügtes Glossar konsultiert oder nicht, ist seine eigene Entscheidung beim Leseprozeß).

\subsection{Zwischen- / fremdsprachliche Kontakte}

Vor dem Hintergrund, daß die innere Mehrsprachigkeit und die innersprachlichen Kontakte als eine Reibungsgröße auffallen und darin die Wirkung von Fachlichkeit und Fachkommunikation als sozialen Führungsgrößen deutlich prägen, haben die zwischensprachlichen, also fremdsprachlichen Kontakte eine gewisse Selbstverständlichkeit erlangt. Ja, es ist auch hier gerade die Fachkommunikation, die sich für die Gesellschaften und ihre Kontakte als die maßgebliche und auszubauende zwischensprachliche Größe herauskristallisiert hat. 
2.6.1. So ist der Bedarf an Deutsch als Fremdsprache im Ausland speziell in dem Sektor 'Fachliches Deutsch oder Wissenschaftsdeutsch' gestiegen, dabei durchaus differenziert nach etlichen Fachgebieten von besonderem Interesse, hier vor allem Wirtschaftsdeutsch. Das Deutsch der Alltagskommunikation ist dabei gar nicht so sehr gefragt, das spezifische Register der Fachlichkeit ist von größerem Reiz, weil nämlich von pragmatischem Belang. Denn die im Handel, in der internationalen Verflechtung, in der industriellen Produktion zusammenarbeitende Welt benötigt die spezifische Kommunikationsfähigkeit im Fach, zumal diese zwangsläufig die Fertigkeiten für die alltagssprachliche Kommunikation mit sich bringt, eben weil die Fachsprache, wie hinreichend bekannt, kein eigenständiges und isoliertes System ist. 76

2.6.2. Diese pragmatisch gewachsenen Differenzierungen haben inzwischen auch die Übersetzungspraxis maßgeblich erweitert: von der alten Dualität des literarischen und nicht-literarischen Übersetzens nun in die beherrschende dritte Komponente des Fachübersetzens; und hier ist die Komplexität der Anforderungen im Sachwissen und in der zugehörigen Sprachkompetenz so stark, daß sich das Fachübersetzen bei der Übersetzungspraxis wie auch in der übersetzungswissenschaftlichen Reflexion trennt in das Fachübersetzen einerseits in den geistesund sozialwissenschaftlichen Fächern, und andererseits in den Naturwissenschaften und der Technik. ${ }^{77}$

2.6.3. Die Auswirkungen zwischensprachlicher Kontakte auf die innersprachliche Mehrsprachigkeit machen sich deutlich bei dem Verhältnis von Englisch zu anderen Sprachen, bzw. von einer Sprache zum Englischen als Fremdsprache. Hier steckt eine hohe soziale Herausforderung, die mit Fachkommunikation ganz eng zusammenhängt. Denn das rasant gestiegene und platzgreifende Prestige der englischen Sprache steht natürlich in kausalem Zusammenhang mit den eigengesetzlich sich entwickelnden Bedürfnissen der fachlichen Kommunikation: die Anglophonie in den Wissenschaften ist inzwischen zwingende Selbstverständlichkeit. Seit 1933 bis weit nach Kriegsende war durch die deutsche und die europäische Emigration von Gelehrten, Wissenschaftlern, Erfindern und den damit verbundenen brain drain also Wissenschaftsausblutung und Vertrocknung der Innovationskraft 
der Forschung - die wissenschaftlich-technologische Führungsrolle der englischsprachigen USA gewachsen, was als Konsequenz mit sich gebracht hat, daß inzwischen weltweit die Forschung, insbesondere die Spitzenforschung in Naturwissenschaften und Technologie, Englisch spricht, wenn es um die Mitteilung von Forschungsergebnissen, um Kooperation und Transfer, um internationale Umsetzung geht. Zwar ist der Begriff des 'Technologietransfers' inzwischen, mit den neunziger Jahren, in selbstbewußtem Respekt vor den beiderseitig anzuerkennenden Leistungen, ergänzt, vielleicht sogar bald ersetzt durch den Begriff des 'Technologiedialogs', wodurch natürlich der Aspekt der Kooperation und des partnerschaftlichen Austausches stärker betont wird, aber dieser Dialog seinerseits wird auf englisch geführt. Die nationalen Wissenschaftssprachen haben da, wenn überhaupt, nur ihre fachlichen Nischen bewahren können, so im Deutschen: Wirtschaft, Archäologie, Theologie, Philosophie, Soziologie, Rechtswissenschaft; im Französischen, noch enger, die Philosophie. Die "wichtigen" und prestigeträchtigen Fächer wie Medizin oder Technik tauschen sich in den verschiedensprachigen Nationen auf englisch aus. ${ }^{78}$

Dieser Zustand einer beherrschenden weltweiten Anglophonie entwickelt sich von der monolingualen Ökonomie zu einer monokulturellen Monotonie, zu einer Monopolisierung auf Kosten der sogen. "kleinen" Sprachen und zu einer Blutleere der Wissenschaftskommunikation in der vielfarbigen und lebendigen Sprachkultur der Kultursprachen Europas und auch - durchaus als Problem zu anderen Wissenschaftstraditionen zu sehen ${ }^{79}$ - außerhalb Europas, so im arabischen und asiatischen Kulturraum. Dies ist eine Gefahr, die inzwischen von der Sprachkritik, der Sprachpflege, der Bildungs- und Sprachpolitik ${ }^{80}$ gesehen worden ist und durchaus kontrovers diskutiert wird. Grundkonsens dabei muß allerdings sein und bleiben, daß die Einzelsprachen, erst recht dann, wenn sie auch als Wissenschaftssprachen dienen, ihre Geltung und ihre Fähigkeiten zur Fachkommunikation behalten, und dies funktioniert natürlich nur und allein im ständigen Einsatz, im konkreten Gebrauch. Ein Modell der gegenseitigen Achtung, das auch den aktuell gegebenen, nicht zurückschraubbaren Entwicklungsstand beachtet, könnte die Lehre und Verwendung von 'Englisch-plus ...' sein. 


\section{Fachlichkeit und Fachsprachlichkeit als forschungsrele- vante Größe (Methodologie)}

Um die Mittel, Leistungen, Möglichkeiten und Bedingungen der Fachsprachen zu erkennen, bedarf es der Forschung, der wissenschaftlichen Analyse, und sie ist dabei selbstverständlich vornehmliche Domäne der Linguistik, hier der Fachsprachenforschung. Sie hat bislang keine eigenen Methoden und Darstellungsmittel entwickelt; vielmehr bindet sie sich ein in die Angebote an Instrumentarien und Methoden, die von den einzelnen linguistischen Disziplinen (wie Phonologie, Lexikologie usw.) erarbeitet worden sind. Indem die Fachsprachenforschung aber diese Angebote nutzt, ermöglicht sie ihrerseits mit ihren spezifischen Forschungsanliegen und Analysezielen eine Verfeinerung, Korrektur oder Ergänzung. Keine andere Herausforderung hat dies so umfassend erbracht wie die der Fachkommunikation: weder die Soziolinguistik, noch die Psycholinguistik, noch die Kommunikationstheorie, noch die Informationstheorie, noch die Semiotik. All deren Beiträge sind im einzelnen gern unbestritten, aber die Fachsprachenforschung dürfte ein ganzheitliches Anforderungsraster für die linguistische Methodologie eingebracht haben, was uns berechtigt, ihr den Status einer forschungsrelevanten Größe zuzubilligen. Er bezieht sich auf die Methodologie,

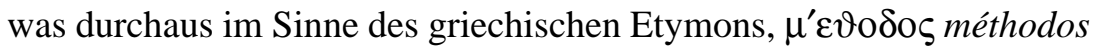
'Weg (etwas zu erreichen)', verstanden werden soll als 'Wege und Wegmarken der Erforschung'.

In diesem Sinne biete ich hier als Orientierungsmarken oder Schlüsselbegriffe jene Aspekte, die über die Fachsprachenforschung der Linguistik neue Konturen gegeben und somit ein gewandeltes Profil verliehen haben:

\subsection{Fachgebundenheit, Sachbezogenheit}

Der referentielle Aspekt ist mit der Fachsprachenforschung dominant in den Vordergrund des linguistischen Interesses gerückt, während die emotive (expressive) Komponente (Sender) und die appellative Komponente (Empfänger) ebenso deutlich zurückgedrängt bleiben und zur Zeit immer noch anderen linguistischen Disziplinen oder Nachbardisziplinen vorbehalten sind, so der Stilistik, der Poetik, der Psycholinguistik, der Literaturwissenschaft, der Medienwissenschaft, der Semiotik. 
Mit der Fachgebundenheit und den außersprachlichen Zentralbegriffen 'Fach' und 'Fachlichkeit' hat die Fachsprachenforschung ihren spezifischen Ausweis, der sich auf das Korrelat 'Fachsprache' bezieht:

\subsection{Systematizität}

Der Begriff 'Fachsprache' ist in den letzten Jahren auf seine qualitativen Merkmale hin befragt worden, was den Begriff der 'Fachsprachlichkeit' hervorgebracht hat. Dieser wiederum hat den Blick vom Sprachsystem mit seinen Funktionsebenen - Phoneme, grammatische Morpheme, Lexeme / Termini, Syntagmen, Syntax, Makrosyntax / Textgliederung / Textstruktur - weiter gelenkt auf textuelle Faktoren (Gliederung, Kohärenz, Verweisformen usw.), auf pragmatische Faktoren (Kommunikanten, Kommunikationssituation), auf die Verbindung von beiden, wie sie sich bei den Textsorten zeigt, auf semiotische Faktoren (Text-Bild-Verhältnis, Körpersprache), schließlich auf kulturell angelegte Spezifika (Formen von Konventionen und Vorerwartungen).

Deshalb verdrängt der komplexere Begriff 'Fachkommunikation' allmählich den systemorientierten Begriff 'Fachsprache', was durch Methoden wie in Klaus-Dieter Baumanns integrativen Analysen (1992) oder durch pragmatische Textsorten-Konzeptionen wie in Susanne Göpferichs dynamischem Modell fachlicher Textsorten (1995) ${ }^{81}$ oder durch fachtextpragmatische Spektren, wie sie in Schröder [Hrsg.] (1993) vorgestellt sind, und Erweiterungen in kulturelle und interkulturelle Dimensionen hinein ${ }^{82}$ sowie durch Einbezug semiotischer Aspekte $^{83}$ und kognitionspsychologischer Erkenntnisse ${ }^{84}$ gefördert wird.

\subsection{Medialität}

Die vorherrschende Stellung der schriftlichen Sprache bei den linguistischen Analysen ist seit Beginn der achtziger Jahren deutlich relativiert worden: das aufkommende Interesse an gesprochener Sprache wird inzwischen auch von der Fachsprachenforschung gestützt und als wichtiger Faktor gesellschaftlicher Kommunikation gesehen. Gerade hier ist ja ein Tummelplatz der Vielsprachigkeit, folglich eine Chance der direkten Verständigung, aber natürlich auch eine Gefahr für persönliche, sachbezogene, situative und kulturelle und interkulturelle Kom- 
munikationskonflikte. Der Einstieg in den Themenbereich 'Mündliche Fachkommunikation' dürfte spätestens mit der Arbeit von Klaus Munsberg (1994) markiert sein.

\subsection{Chronizität (Diachronie / Synchronie)}

In den letzten fünfzig Jahren linguistischer Forschung hat das Interesse für die Synchronie das ehemals dominierende Interesse für die Diachronie stark verdrängt. Die Gründe sind im Paradigma des Strukturalismus nach dem Krieg zu suchen, ebenfalls in der platzgreifenden Soziolinguistik der späten sechziger und der siebziger Jahre, schließlich in der Fachsprachenforschung selbst, die sich ab den ausgehenden sechziger Jahren als eine Disziplin mit direktem, aktuellem, unmittelbar lebenspraktischem Bezug verstand.

Daß die Diachronie aber nicht zu einem Teilinteresse der Philologien verkümmert, wird nun - und dies aus der Sicht der Fachsprachenforschung! - neu betrieben, indem die Diachronie, die Licht auf historische Sprachstufen wirft, als Ergänzung gefordert wird ${ }^{85}$ und sich übrigens auch schon in früheren Untersuchungen 86 - mit komplexen Erkenntnisgewinnen bewährt. ${ }^{87}$ Die Attraktivität, die hierbei noch eingebracht werden kann, sind gesellschaftsgeschichtliche, arbeitsgeschichtliche, kulturhistorische Aspekte, aus denen heraus sich alte fachsprachliche Phänomene neu sehen und als Ergebnisse von Entwicklungen und Traditionen für ein komplexeres Verständnis bewerten lassen.

\subsection{Applikabilität (Gesellschaftsbezug)}

Eine der offenkundigsten Rechtfertigungen der Fachsprachenforschung im Zusammenspiel der linguistischen Disziplinen ist ihre unmittelbare und mittelbare Praxis-Relevanz. Schon eine ihrer direkten ZuträgerDisziplinen, die Sprachstatistik, hat sich aus ihrem Anwendungsaspekt heraus definiert. In der evidenten praktischen Umsetzung - und aus dieser heraus, in der Rückwirkung aus der Praxis in die wissenschaftliche Analyse - liegt die Chance und die besondere Attraktivität der Fachsprachenforschung. In ihrem solchermaßen beglaubigten Status als Disziplin der Angewandten Linguistik ist sie die zur Zeit am raschesten wachsende Disziplin, und ihr Einfluß in der Gesellschaft ${ }^{88}$ und auf die Kommunikation in den Institutionen ${ }^{89}$ sowie ihre Ausstrah- 
lung auf bildungspolitische Entwicklungen insbesondere in der Sprachund Fremdsprachenvermittlung ${ }^{90}$ ist nicht mehr zu übersehen, ja ist inzwischen eine breitenwirksame Selbstverständlichkeit, wie sich an gesellschaftlich ausstrahlenden Arbeitsfeldern - so an der Wissenschaftsethik ${ }^{91}$ oder der Technikfolgen-Abschätzung (Technical/Technology Assessment $)^{92}$ oder dem Wissenschaftsjournalismus ${ }^{93}$ - ablesen läßt.

\subsection{Semiotizität}

Für die Fachsprachenforschung war es zwar zunächst nicht selbstverständlich, andere Zeichen als die (schriftlich-) sprachlichen auch noch in Betracht zu ziehen, aber inzwischen sind das fachbezogene Formelinventar, die speziellen Notationsweisen, die Graphiken und die fachlichen Bilder als unverzichtbare (schriftliche) Kommunikationsformen "im Fach" erkannt. Diesen Phänomenen widmet sich, wie ich sie genannt habe ${ }^{94}$, die Fachsprachensemiotik oder fachkommunikative Semiotik (oder Semiotik der Fachkommunikation).

Dann aber umfaßt sie natürlich auch die mündliche Fachkommunikation mit den dortigen nonverbalen Zeichen, also die fachliche oder wohl besser: die fachbezogene Körpersprache.

Die Nähe der Zusammengehörigkeiten und die dichten Bezüge werden deutlich, wenn man sieht, daß die für die Fachkommunikation maßgebliche Qualität 'Fachlichkeit' (a), das Verhältnis von Text und Bild (b), die Mündlichkeit (c) (s. 3.3.), die Interdisziplinarität (d) (s. 3.7.2.) und die interkulturelle Vergleichbarkeit von Fachtexten (e) (s. 3.7.3.), ebenso die Rhetorik mit Argumentationsstrukturen und Metaphern (f) und inhaltlichen Komprimierungen ("Abstracts", "Zusammenfassungen") (g) Themen sind, die letztlich die Zeichenqualitäten $\left(a^{\prime}\right)$, Zeichengemeinschaften ( $\left.b^{\prime}\right)$ und Zeichenformen ( $\left.c^{\prime}\right)$, den Zeichenaustausch (d') und die Zeichenbeziehungen (e') sowie die Verwendungsweisen (f') und Einsatzbedingungen und -wirkungen (g') von komplexen Zeichen betreffen, aber eben hier speziell in ihren jeweiligen fachbezogenen Kontexten.

Derartige semiotische Fragestellungen führen zwangsläufig dazu, die Kulturspezifik zu erkennen. Hierzu hat die Fachsprachenforschung der Linguistik wichtige Anstöße gegeben (Wirtschaftskommunikation, Werbung, Kommunikationspragmatik, Kulturemforschung $)^{95}$ und das 
Forschungsfeld - sogar institutionell - beträchtlich erweitert: die Interkulturelle Wirtschaftskommunikation ${ }^{96}$ gilt als inzwischen etabliert und entwickelt sich über die rein sprachlichen und textuellen sowie textsortenbezogenen Untersuchungsinteressen auch weiter zu Fragen des kommunikativen Umgangs und des interkulturell sensiblen Aushandelns gelingender Fachkommunikation ${ }^{97}$.

\subsection{Kontrastivität}

Die vorgeführten sechs Punkte (3.1. bis 3.6.) von forschungsrelevantem Einfluß der Fachsprachenforschung lassen sich verbinden mit einer prinzipiellen methodologischen Klammer: sie lautet 'Kontrastivität'. Ihre zentrale Stellung in der Fachsprachenforschung hat auch auf die Linguistik allgemein ausgewirkt: die Zeiten jedenfalls, in denen man noch mit ausschließlich engem Blick auf das Englische durchgreifende Sprachtheorien verkünden konnte (Beispiel Chomsky der auslaufenden sechziger Jahre), sind wohl endgültig vorbei. ${ }^{98}$

Die kontrastive Grundhaltung hat ihre Leitbegriffe: es sind dies die 'Intertextualität', 'Interdisziplinarität' und 'Interkulturalität':

3.7.1. Die Intertextualität - der Begriff geht auf die Literaturwissenschaftlerin Julia Kristeva (1969) der Gruppe Tel Quel zurück und ist durch Broich / Pfister [Hrsg.] (1985) insbesondere propagiert worden - meint die Abhängigkeitsbeziehungen und inhaltlichen Aufruf-Bezüge zwischen Texten bzw. Textsorten und ihren schriftichen und mündlichen Vorgängertexten und Vorgängertextsorten (bzw., was die Literaturwissenschaft bevorzugt: Gattungen) ("types d'énonces") 99 , wie sie als eine bewußt wahrnehmbare Filiation von Texten vom Autor intendiert sind und darin eine wiedererkennende Rezeptionserwartung aufbauen ${ }^{100}$. In diesem verkettenden Wechselspiel bildet sich eine Textetradition heraus, an die letztlich auch der Begriff der Konvention, der die Textsorten (Gattungen) auszeichnet, angebunden ist. ${ }^{101}$

3.7.2. Die Interdisziplinarität meint den gegenseitigen Erfahrungsund Erkenntnisaustausch zwischen den Fächern. ${ }^{102}$ Das ist eine große Herausforderung, da dieser Austausch natürlich seinerseits auch nur wieder mit Sprache ablaufen kann, und zwar dann in verständlicher 
Vertextungsweise, um Verständigung aufbauen zu können, die ihrerseits zu gegenseitigem Verständnis führt. Hier stehen wir wieder an dem Punkt 'Verständlichkeit als eine soziale Führungsgröße'.

Die gegenseitige Achtung und die Bereitschaft, methodologisch aufeinander zuzugehen und inhaltlich einander auch zuzuhören, sind gefordert; und dabei natürlich auch eine bescheidene Selbsteinschätzung: einige Kenntnisse aus dem fremden Fachgebiet machen noch nicht den Fachmann des Gebietes aus. Dies ist Dilemma wie Chance für die Fachsprachenforschung, die wieder Brückenschläge zwischen den seit Wilhelm Dilthey (1838 - 1911) begrifflich in ihrem Selbstverständnis getrennten Natur- und Geisteswissenschaften ${ }^{103}$ schaffen will und dabei zu einer neuen Konfiguration der Wissenschaften zueinander, ohne pragmatisch scharfe oder ideologisch gezogene Grenzen, beitragen möchte. 104

Die Frage, wie weit ein an Fachsprachen interessierter Linguist auch z.B. ein kenntnisreicher Ingenieur sein sollte oder (bei Übersetzungsleistungen und terminologischen Klärungen) es auch sein muß; und umgekehrt: wie weit von einem Mediziner oder einem Kernphysiker erwartet werden darf, daß er sich auch mit sprachlichen Problemen - so mit den Herausforderungen seiner Terminologien, seiner Sprechweisen, seiner Textkonventionen, seines Adressatenbewußtseins bei der Kommunikation, usw. - kritisch beschäftigt, bleibt im generellen noch unbeantwortet, regelt sich aber sehr oft und inzwischen erfreulich zunehmend durch das persönliche Interesse an interdisziplinären Erweiterungen und transdisziplinären Kooperationen. Zwar sind in der Wissenschaftskommunikation, wie Schröder (1995:177) den JakobsonSchüler Elmar Holenstein zitiert, tatsächlich "Universalisierung und Partialisierung zwei Phasen eines Zyklus, der grundsätzlich immer wieder von neuem durchlaufen werden kann"; doch sollte hier grundsätzlich als ein Leitmotiv für die Kommunikation im Fach und zwischen den Fächern das schöne Dictum von Ernst Robert Curtius (111993: 10) Beachtung finden: "Spezialismus ohne Universalismus ist blind. Universalismus ohne Spezialismus ist eine Seifenblase."

3.7.3. Die Interkulturalität meint das Herauspräparieren und Vergleichen von Kulturspezifika, d. h. Kulturemen. Sie beziehen sich auf Vorkenntnisse, Vorerfahrungen, Verhaltensweisen, Erwartungshaltungen, Einschätzungsgrößen, Gewohnheiten, die bei der Kommuni- 
kation im Fach vorhanden sind und sich im internationalen Austausch konfliktionär auswirken können. Es gilt daher, das Fremde im Vergleich zum Eigenen zu erkennen, es dort zu verstehen und in die Verstehensprozesse mit einzubeziehen. Hierzu wäre eine Kulturem-Didaktik vonnöten. ${ }^{105}$ Sie wäre gerade in der Fachsprachenforschung als Teil ihrer Didaktik sinnvoll, da die meisten kulturellen Kommunikationskonflikte bei der fachlichen Kommunikation, z. B. bei internationalen Wirtschaftsbeziehungen, auftreten und dann als tiefgreifende Störungen sogar wirtschaftliche Nachteile (z. B. verhinderte Vertragsabschlüsse) zur Folge haben können. ${ }^{106}$

\section{Fachlichkeit und Fachsprachlichkeit als Zukunftsgröße}

Welche Konsequenzen ziehen wir nun aus den Überlegungen zur Fachlichkeit und Fachsprachlichkeit als sozialer Führungsgröße und als forschungsrelevanter Größe?

Ich meine, Gründe genug dafür vorgestellt zu haben, die Fachsprachen als eine Zukunftsgröße etikettieren zu dürfen. Dieses Etikett birgt die Prognose auf wachsenden Einfluß und auf platzgreifende Bedeutung in der und für die Kommunikation in und zwischen den Gesellschaften.

4.1. So ist diese Zukunftsgröße zunächst einmal eine Anspruchsgröße: Mit gesteigerter Bildung muß es die Gesellschaft lernen, mit der Multilingualität so umzugehen, daß die Sprache die Teilhabe aller gewährleistet und daß nicht kommunikative Zäune errichtet werden und dies geschieht ja, wir erinnern uns an die begriffsgeschichtlichen Ausführungen eingangs, über die Fächer. Der Konflikt zwischen Fachleuten und Laien durch Nicht-Verständlichkeit und durch NichtVerstehen soll, so der Anspruch, durch bewußte Sprachgestaltung und Partnerbezug vermieden werden: Bringschuld der Fachleute und Holschuld der interessierten Laien sollen sich ergänzen.

4.2. Diese Basis des gesellschaftlichen Konsenses durch transparente Kommunikation ist auch deshalb so wichtig, weil sie auch Grundlage und Ausgangspunkt für die Fachsprachenforschung als Reflexionsgröße ist. Dies zeigt sich in Anstößen und Überlegungen aus der Wissenschaftsethik (s. 3.5.), aus der Kritik der Fach- und Wissen- 
schaftssprachen (Anglophonie-Problem!) (s. 2.6.3.), aus der rührigen Wissenschaftssprachstilistik (s. 2.5.2.).

4.3. Derartige Dimensionen sind allerdings nur nahegelegt, wenn wir inzwischen wirklich den Stand erreicht haben, die Fachsprachen als Integrationsgröße ansehen zu können. Ich sehe dies gewährleistet, indem wir das Forschungsobjekt komplex formulieren, nämlich als:

\section{'Fachsprachen-in-Texten-und-Kommunikationssituationen-und- Kultur'.107}

Die Integrationsgröße 'Fachsprachen' kann man vor diesem komplexen Hintergrund im Anschluß an die Prager Linguisten und nach der Wiederbelebung durch Harald Weinrich (1985) somit durchaus berechtigt verstehen als ein Kernstück von 'Sprachkultur'. Dies wäre eine exzellente Placierung in einem vornehmen Rahmen. Aber so, wie dieser Platz in rund dreißigjähriger Forschung und Lehrpraxis erarbeitet worden ist, muß er natürlich auch gepflegt werden:

\section{Ausblick: Fachkommunikation}

Verknüpfen wir doch die Zukunftsgröße (Kap. 4.) mit der mentalitätsgeschichtlichen Größe (Kap. 1.) und schließen mit der Suche nach einer Allegorie für die Fachsprachenforschung der Jetztzeit und der Zukunft. Sicher muß sie anders aussehen als die marmorne $\Sigma o \varphi^{\prime} 1 \alpha$. Ich stelle mir, als imaginärer Bildhauer, die moderne Allegorie der aktuellen Fachsprachenforschung so vor:

- Sie wirkt nicht statuarisch-gemessen, sondern dynamisch-lebendig;

- sie zeigt sich mit offenen Armen, die - körpersprachlich signifikant von sich weitergeben und für sich empfangen;

- und sie schaut nicht über alles und alle hinweg in die unkonkrete Ferne, sondern sie schaut uns an, als Partner, mit einem kommunikativen Gesicht.

Und ich würde meine Allegoria nicht ins Kunsthistorische Museum stellen, auch nicht ins Museum moderner Kunst, nein, sie käme auf den Marktplatz, auf die agorá, griech. $\alpha \gamma o \rho^{\prime} \alpha$, das Forum, also auf den altangestammten Platz für soziale Kommunikation und Interaktion, wo man sich sieht, sich austauscht, fachlich handelt und alltäglich wie auch 
fachsprachlich spricht, eben weise, kenntnisreich und geschickt ist, oder wie die Griechen in einem solchen Umfeld von techné und epistéme sagten: mit sophía.

1 S. “Der Kleine Pauly” I (1979: 893 f., s.v. Bibliothek[en], 892-896).

2 Den Sophía-Typus findet man auch im Pariser Louvre, in der Ermitage von Leningrad, im British Museum in London, in Florenz (Corsini), Rom (Forum; V. Doria Pamfili) und Stratonikeia [Kleinasien]. Dazu s. Linfert (1976: 163, Fn. 649; 201; 207f.; 211; 218; 220f.). Inventar-Nr. 948 (nach Linfert 1976: 163, Fn. 649, Nr. 4); Standort-Nr. im Museum: 159.

3 Nach dem “Catalogue Sommaire des Marbres Antiques” Nr. Fröhner [W. Fröhner: "Notice de la Sculpture Antique”]; Angaben aus Linfert (1976: 211).

4 Die hellenistische Epoche setzt - gemäß Johann Gustav Droysen - ein mit der Zeit Alexanders des Großen (Gründung von Alexandreia 331 v. Chr.).

5 Die klassische Zeitspanne wird ausgezeichnet von Tragikern wie Aischylos, Sophokles und Euripides; von dem Komödiendichter Aristophanes; vom Format der Geschichtsschreiber Thukydides und Xenophon. Die großen attischen Rhetoren wie Isokrates oder Demosthenes prägen sie, und die dreigliedrige Kette der berühmtesten Philosophen - Sokrates, Platon, Aristoteles - legt den Grund für das abendländische Denken. - Zur Allegorisierung abstrakter Begriffe durch Personifikationen in jener Zeit s. Shapiro (1993).

6 Der Begriff der 'Wissenschaft' ist über die Vermittlung der Griechen ein europäischer, wohl besser: abendländischer Schlüsselbegriff geworden, der in Kontrast $\mathrm{zu}$ dem Wissenschafts-Begriff anderer Großkulturen, so der arabischen und der chinesischen bzw. asiatischen, steht. Kern des abendländischen Verständnisses von 'Wissenschaft' ist der aristotelische epistéme-Begriff, der sich beherrschend bestimmt aus den Komponenten 'Wahrheitssuche' (griech. $\alpha \lambda$ ' $\vartheta \varepsilon \imath \alpha$, alétheia 'Wahrheit') und 'Beweisbarkeit' (mit griech. v'ovs, nous 'Einsicht', 'Verstand', 'Vernunft').

Diese sind Werte an sich; "sie werden weder theologisch fundiert noch sozialen Nützlichkeitserwägungen untergeordnet. In der europäischen Renaissance kamen zu dem - in der latinisierten Form scientia - wiederbelebten antiken Begriff zwei weitere konstitutive Merkmale hinzu: das wiederhol- und nachprüfbare Experiment (Francis Bacon); und die Mathematisierung / Quantifizierung (Kepler, Galilei): Gerade diese beiden Bestimmungselemente erlangten dann für den beispiellosen, die anderen Hochkulturen rasch überflügelnden Aufschwung der europäischen Wissenschaft im 17. und 18. Jahrhundert entscheidende Bedeutung. [...] 'Wissenschaft' als rationale Wahrheitssuche mit experimentellen und mathematischen Methoden." (Bossong 1992: 84).

7 "Paulys Real-Encyclopädie der classischen Altertumswissenschaft" (1927: 1019, s.v. Sophia, 1019-1039).

8 Xenophanes von Kolophon (*ca. 580 v.Chr.); Herakleitos von Ephesos (ca. 535 475); Parmenides aus Elea (*ca. 515 v.Chr.); Demokrítos aus Abdera (*ca. 470 v.Chr.); u.a. - S. auch Snell (1924).

9 "Paulys Real-Encyclopädie der classischen Altertumswissenschaft" (1927: 1020, s.v. Sophia, 1019-1039). 


\section{8}

10 Sokrates (469 - 399 v.Chr.); Platon (427 - 347 v.Chr.); Aristoteles (384 - 322 v.Chr.).

11 Das Christentum wird dies später nach einer jahrhundertelangen Tradition steter "Theologisierung" seinerseits aufnehmen und die Weisheit Gottes als Hagía Sophía, 'A $\gamma^{\prime} 1 \alpha \Sigma o \varphi^{\prime} 1 \alpha$ 'Heilige/Göttliche Weisheit', verehren; s. "Der Kleine Pauly" V (1979: 270f., s.v. Sophia, 270f.). Die Philosophie wird in der christlichen Ikonographie meist als eine stehende oder - die Königin der artes liberales - als thronende Frau dargestellt, die alle anderen artes nährt und - sich in deren Zentrum oder, je nach Bildanordnung, an deren Spitze befindend - schützt ("Lexikon der christlichen Ikonographie" III (1990: 429, s.v. Philosophie, 428-430). Während die Philosophie durchaus Gefahr lief, im Mittelalter auch als "Mutter der Häresie" eingeschätzt zu werden, und während sie als solche sogar auch in Buchillustrationen personifiziert ist (Abbildung z.B. im gerade zitierten LCI III (1990: 429), fand die Sophía 'Weisheit', in der lateinischen Form des Mittelalters dann Sapientia, eine positive begriffliche Stützung im Kontext von 'Seligkeiten', 'Tugenden', somit von 'Christus' und 'Maria'. Dementsprechend, gestützt durch den o.g. Begriff der 'Göttlichen Weisheit', zeigt sich Sapientia ikonographisch meist als "reichgekleidete, gekrönte, nimbierte Frau" ("Lexikon der christlichen Ikonographie" IV (1990: 40, s.v. Sapientia, 39-43), oft gemeinsam mit Fides (griech. $\pi^{\prime} \imath \sigma \tau \iota \zeta$, pístis 'Glaube'), Caritas (griech. $\alpha \gamma^{\prime} \alpha \pi \eta$, agápe 'Nächstenliebe') und Spes (griech. $\varepsilon \lambda \pi^{\prime} \iota \varsigma$, elpís 'Hoffnung'), die als ihre Töchter, als Töchter der Weisheit, gelten und die drei theologischen Tugenden repräsentieren. Eine gewisse ikonographische Annäherung zwischen Philosophia und Sapientia in ihrer Personifikation, ihrem Habitus, ihrem Umfeld und ihren Attributen mit den allegorischen Aussagen läßt zur Renaissance hin die Grenzziehungen des Mittelalters zwischen ihnen verblassen. Die Barockzeit sieht sie dann vorzugsweise im Kreise von Tugenden und Allegorien und malt sie in ethisch geprägter Grundhaltung gern an die Decken von Bibliotheken (LCI IV 1990: 42).

12 Deren Inschriften berichten, daß sie die Eigenschaften des Bibliotheksgründers Celsus verkörpern. Informationen zu Sophía, Epistéme und Énnoia als künstlerische Personifikationen in: "Lexicon Iconographicum Mythologiae Classicae” (LIMC) VII/1 (1994: 798 zu sophía), III/1 (1986: 809 zu epistéme, und 743 zu énnoia).

13 Inventar-Nr. 881 (nach Linfert 1976: 21, Fn. 36, Nr. b); Standort-Nr. im Museum: 162. (Römisch, 2. Jahrh. n. Chr., nach hellenistischen Vorbildern des 3. Jahrh. v. Chr.).

14 Inventar-Nr. 852 (nach Linfert 1976: 64, Fn. 77); Standort-Nr. im Museum: 160. (Römische Kopie nach hellenistischem Original um 170 - 150 v. Chr.).

15 Inventar-Nr. 918 (nach Linfert 1976: 161, Fn. 641, Nr. 36); Standort-Nr. im Museum: 161. (Römische Kopie nach hellenistischem Original des 2. Jahrh. v. Chr.).

16 Vgl. "Paulys Real-Encyclopädie der classischen Altertumswissenschaft" (1927: 1023, s.v. Sophía, 1019-1039).

17 Die kultursoziologischen Aspekte hierzu sind von Trier (1951) sehr luzide aufgearbeitet worden; einbezogen in Kalverkämper (1992 a).

18 Kalverkämper (1990 a: insbes. 88-99; 1992 a: insbes. 31-42).

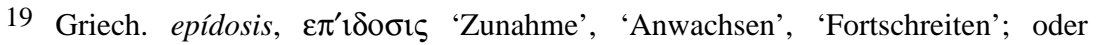
prokopé, $\pi \rho о к о \pi ' \eta$ 'Gedeihen', 'Fortschritt' (vgl. Meier 1975).

20 Das Denkmodell der Weitergabe bezieht sich auf die politische (translatio imperii) und damit dann auch auf die kulturelle Vormachtstellung im Wettstreit der Nationen und Kulturen. Mit einem ausgeprägten Bewußtsein für historische Kontinuität und Kulturverbundenheit wurde und wird sie je nach Sichtweise bei den Babyloniern oder 
(dann) bei den Ägyptern als Ursprung angenommen; sie wechselte von dort zu den Medern/Persern, um anschließend in einer Ost-West-Bewegung an die Griechen zu gehen, die ihrerseits sie an die Römer weitergaben, um schließlich von den Franzosen bzw. den Spaniern bzw. den Deutschen übernommen zu werden. Vgl. Goez (1958).

21 Hierzu hervorragend Lausberg (1960 I: §§ 1-5 und weiter bis § 31).

22 Vgl. Eis (1960, ${ }^{2}$ 1967); Koch (1959); Assion (1973); Keil / Assion (1974); Keil / Assion / Daems / Roehl [Hrsg.] (1982).

23 Hierzu Böhme (1984,1986); Christes (1975); Dolch (1982); Müller (1969).

24 Es ist interessant, daß gegenüber den artes liberales die mechanischen Künste als Zyklen recht wenig dargestellt werden und sich (bis auf medicina und architectura) kaum personifiziert (z.B., wie üblich, als weibliche Personen mit Attributen) finden, was z.B. an Kathedralen oder Burg- und Schloßbauten möglich gewesen wäre. In Gemeinschaft mit den personifizierten artes liberales kommen sie vielmehr in Tätigkeitsbildern vor. Vgl. "Lexikon der christlichen Ikonographie” II (1990: 701-703, s.v. Künste, mechanische; 703-713, s.v. Künste, Sieben Freie).

25 Dies bezieht sich auf Anzahl und Zugehörigkeiten von Fächern. Auch ist es interessant, daß die allegorischen Figuren der artes gemäß der femininen Genera (grammatica, rhetorica etc.) auch Frauenfiguren sind, so im 13. Jahrhundert; daß aber gegen Ende des 15. Jahrhunderts nicht mehr Frauen, sondern Männerdarstellungen diese göttliche Welt- und Wissensordnung repräsentieren (Abbildung dazu z.B. in Schiffler / Winkeler ${ }^{3}$ 1991: 22).

26 Furet (1965: 31, dort Anm. 27).

27 Kalverkämper (1983a); Merton (1983).

28 Kalverkämper (1992 a).

29 Die Wichtigkeit dieser Präzisierung auf die zu berücksichtigende Kulturengebundenheit hin und gegen eine ungeprüfte Universalien(hypo)these zeigt sich an den Forschungsbeiträgen von Bossong (1992); Clyne (1987, 1993); Galtung (1985); Krusche / Wierlacher [Hrsg.] (1990); Müller [Hrsg.] (21993); Schröder [Hrsg.] (1993); Spillner [Hrsg.] (1990); Wierlacher [Hrsg.] (1985); u.a.; vgl. auch die Bibliographie von Hinnenkamp (1994).

30 Hierzu sollte im Bewußtsein bleiben, daß Kriterium und Kritik auf die gleiche griechische Basis zurückgehen, nämlich kritérion (griech. $\kappa \rho \imath \tau$ ' $\eta \rho ı v$ 'entscheidendes

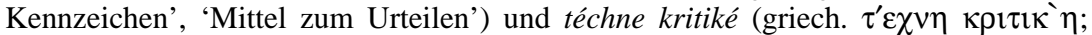

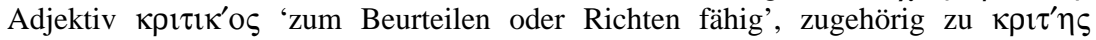

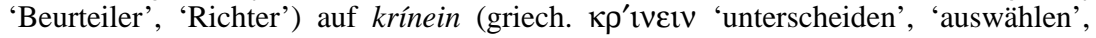
'entscheiden'/'urteilen').

Dem Begriff 'Kriterium' ist der fachbezogene, fachliche, fachmännische Aspekt eigen, wenn er (wie z.B. in "DUDEN. Deutsches Universalwörterbuch". 2., völlig neu bearb. u. stark erw. Aufl. Mannheim - Wien - Zürich: Dudenverlag 1989) s.v. Kriterium unter Nr. 1. definiert wird als: "(bildungsspr.), unterscheidendes Merkmal als Bedingung für einen Sachverhalt, ein Urteil, eine Entscheidung", und dies gilt ebenso für den Begriff 'Kritik' mit der Angabe s.v. Kritik 'Kunst der Beurteilung' unter Nr. 1 a): "(fachmännisch) prüfende Beurteilung und deren Äußerung in entsprechenden Worten".

31 Kalverkämper (1992 a: 42).

32 Kalverkämper (1992 a: 50-53).

33 Kalverkämper (1992 a: 55). 
34 "Vom Wehrbeitrag bis zu Friedensmissionen. Zur Geschichte der sprachlichen Legitimierung und Bekämpfung von Rüstung und Militär." (129 - 162). Als Zeugnis für die hier angesprochene Scheitelstellung zwischen fachlichem Anliegen, fachsprachlicher Kommunikation und Öffentlichkeit der betroffenen bzw. engagierten bzw. interessierten Laien und Sach- sowie Polit-Experten zu einem Thema, das zwischen etlichen verschiedenen Gebieten unterschiedlicher Fachlichkeit angesiedelt ist, muß man unbedingt noch hinweisen auf Burkhardt / Hebel / Hoberg [Hrsg.] (1989). 35 "Zwischen Re-education und Zweiter Bildungsreform. Die Sprache der Bildungspolitik in der öffentlichen Diskussion." (163 - 209).

36 “Amerikanismen, ausländische Wörter, Deutsch in der Welt. Sprachdiskussionen als Bewältigung der Vergangenheit und Gegenwart." (245 - 283). Zu dieser zentralen gesellschaftlichen Fragestellung im Überschneidungsbereich von Fachlichkeit, Fachsprachlichkeit (meist eher: Termini-Gebrauch), Verständlichkeit (Transparenz und Verstehen), (Sozial-)Prestige, Kommunikationszwängen (z.B. in den anglophonisierten Wissenschaftssprachen, in der sogen. Spitzenforschung) und sprachlicher Monokultur vgl. auch Kalverkämper / Weinrich [Hrsg.] (1986) sowie Skudlik (1990) und Oksaar / Skudlik / von Stackelberg (1988).

37 "Die Terminologie der Sexual- und Partnerschaftsethik im Wandel." (593 - 618).

38 Die systematischen und historischen Zusammenhänge dieser Formel im Deutschen wie im Englischen bietet Seiffert (1990).

39 Es sei nur auf die drei Bände "Der öffentliche Sprachgebrauch" der Deutschen Akademie für Sprache und Dichtung (1980-1982) verwiesen.

40 'Landschaft' - aus der Sicht des Malers, des Geographen, des Bauern, des Umweltschützers, der Verkehrsplaner, der Industrie, usw. usw. (vgl. Hard 1970, auch Raible 1979); oder auch 'Heimat' oder 'Kultur' - das sind aktuell virulente Beispiele, in diesem Fall auf der Ebene der Abstrakta. -

Bei Raible (1981: 29) findet sich der an Thomas von Aquin anknüpfende Hinweis, die Fachlichkeit entstehe dadurch, "daß ein bestimmter Sachverhalt durch die Brille eines Systems gesehen wird, eines Systems, das den modus recipiendi steuert, das also dafür verantwortlich ist, was gesagt und was nicht gesagt wird." Das ist vor dem Hintergrund des oben Dargestellten sicherlich zu unterstreichen, sollte aber noch ergänzt werden durch zwei wichtige Gesichtspunkte: nämlich zum einen durch die Tatsache, daß auch der Prozess der Produktion einbezogen werden muß, denn der ist Voraussetzung für die Rezeption und setzt für diese bereits semantische Weichenstellungen (oder, um im Bild der 'Brille' zu bleiben: verlangt bestimmte Gläserstärken für den Lese- und somit Verstehensprozeß); und zum anderen durch die Präzisierung des Rezeptionsbegriffs: Ist es, wie der gerade genannte Ergänzungspunkt nahelegt, wirklich (nur) die Rezeption und somit der Rezipient (Hörer, Leser) im Kommunikationsprozeß, oder ist es nicht eher auch noch jene Rezeption, die der Autor als eine maßgebende Voraussetzung vor seinem Produktionsprozeß, also vor seinem Schreiben über einen Sachverhalt hat und aus der - aus ihrer Einstellung, ihrer Perspektivierung auf die darzustellende Sachlage hin - der Autor seine jeweilige sprachliche Auswahl und seine inhaltlichen Entscheidungen trifft (was man heutzutage kognitionspsychologisch mit Wissenssystemen etc. einbezieht). Jedenfalls setzt die Position des Modus auf die Kommunikanten. Als sich möglicherweise nachteilig auswirkende Schwierigkeit bleibt dabei, daß viele Aussagen zu den personenbezogenen Modi Spekulation bleiben müssen und auch Gesichtspunkte des Mißlingens, der nicht gelungenen Bemühung, unberücksichtigt bleiben. -

Es gibt neben den Kommunikanten noch den Text, seinerseits natürlich abhängig von diesen, aber als eine für Aussagen zur Fachlichkeit faktische, weil konkret vorhandene, 
eben empirische Basis. Deshalb läßt sich, gleichsam anders herum, von hier aus, aber dann mit einem dynamischen 'Text'-Begriff (mit Reizwörtern wie 'Kooperation', 'Dialogangebot', 'Signale', 'Autor-Text-Rezipient-Interaktion' u.a.), das Problem in den Griff nehmen: der Text ist es mit seinen dazu funktionierenden Signalen, der seinen Fachlichkeitsgrad signalisiert, eben als seine Qualität, aber diese als eine Entscheidung des Textautors, der seinerseits dadurch kundtut, welche Rezipientenschaft er für diesen Text antizipiert hat; und dies wiederum erkennt der Rezipient im Leseprozeß und reagiert entsprechend: mit Verständnis, mit Interesse, mit Langeweile, mit Unverständnis, mit Weiterlesen, usw. usw. Die Beschreibung berücksichtigt demnach alle beteiligten Komponenten, und die entstehende Komplexität im Kommunikationsprozeß wird somit zu einem integrativen Merkmal der Untersuchung funktionierender Fachlichkeit in Texten (s. Kalverkämper 1988, hier insbesondere S. 164 mit dem Fazit und weiteren bibliographischen Hinweisen). -

Grundsätzlich klar sollte, nochmals betont, sein, daß die Fachlichkeit keine naturgegebene Eigenschaft des außersprachlichen Objekts, Sachverhalts, Handlungszusammenhangs ist.

41 Zitiert nach Hans Ritz: "Die Geschichte vom Rotkäppchen. Ursprünge, Analysen, Parodien eines Märchens." 10., abermals erw. und neu bearb. Aufl. Göttingen: Muriverlag 1992, hier S. 141 f. - Da das Gemeinte, erst recht als Parodie, sich nicht allein über einen Satz mitteilt, hier noch weiterer Kontext zur Illustration: "Der Mutter besagter R. wurde seitens ihrer Mutter ein Schreiben zustellig gemacht, in welchem dieselbe Mitteilung ihrer Krankheit und Pflegebedürftigkeit machte, worauf die Mutter der R. dieser die Auflage machte, der Großmutter eine Sendung von Nahrungs- und Genußmitteln zu Genesungszwecken zuzustellen. Vor ihrer Inmarschsetzung wurde die R. seitens ihrer Mutter über das Verbot betreffs Verlassens der Waldwege auf Kreisebene belehrt. Dieselbe machte sich infolge Nichtbeachtung dieser Vorschrift straffällig und begegnete beim Übertreten des amtlichen Blumenpflückverbotes einem polizeilich nicht gemeldeten Wolf ohne festen Wohnsitz. Dieser verlangte in gesetzwidriger Amtsanmaßung Einsichtnahme in das zu Transportzwecken von Konsumgütern dienende Korbbehältnis und traf in Tötungsabsicht die Feststellung, daß die R. zu ihrer verschwägerten und verwandten, im Baumbestand angemieteten Großmutter eilend war. Da wolfseits Verknappungen auf dem Ernährungssektor vorherrschend waren, faßte er den Entschluß, bei der Großmutter der R. unter Vorlage falscher Papiere vorsprachig zu werden. Weil dieselbe wegen Augenleidens krank geschrieben war, gelang dem in Freßvorbereitung befindlichen Untier die diesfallsige Täuschungsabsicht, worauf es unter Verschlingung der Bettlägerigen einen strafbaren Mundraub zur Durchführung brachte. [...]."

42 Jens Peter Gieschen / Klaus Meier: "Strafakte Faust. Goethes berühmte Triebtäter auf dem juristischen Prüfstand. Tathergang - Schuldfrage - Anklageschrift." Frankfurt/M.: Eichborn 1993.

43 Um zu zeigen, daß dies keine Fiktion am Schreibtisch ist, hier zwei attraktive Beispiele eines Autors: Leonhard Reinirkens: "Die kulinarischen Abenteuer des Fra Bartolo.” 2. Aufl. Weil der Stadt: Hädecke 1988 (1. Aufl. 1987); ders.: "Großtante Hortense. Bowlen, Punsche \& Amouren.” Weil der Stadt: Hädecke 1985.

44 In diesem Sinn z.B. Christoff Neumeister: "Das antike Rom. Ein literarischer Stadtführer.” München: Beck 1991. Oder Mona Wodsak [Hrsg.]: "Poetischer ParisFührer." Zusammengestellt, eingeleitet und mit Kommentaren versehen von Mona Wodsak. Französisch \& Deutsch. Darmstadt: Wissenschaftliche Buchgesellschaft 1994. 


\section{2}

45 Wie z.B. vorgeführt von Jostein Gaarder: "Sofies Welt. Roman über die Geschichte der Philosophie.” Aus dem Norwegischen von Gabriele Haefs. München - Wien: Hanser 1993 (Norwegisches Original: Oslo 1991).

46 Hierzu Kalverkämper (1989, 1996).

47 Man denke z.B. an "Germinal”, den dreizehnten Roman des Zyklus 'Les RougonMacquart' von Émile Zola (1840 - 1902), erschienen 1885, in dem fachspezifische Bergwerks- und Minenabbautechnik detailliert beschrieben wird, aber ohne daß dies dem Roman das Gepräge einer fachwissenschaftlichen Darlegung aufzwingt. - Für die vorhergegangenen Epochen, die Romantik und die Klassik, sei, wiederum nur als ein zum Weiterdenken anregendes Beispiel, an Goethes Roman "Die Wahlverwandtschaften”, erschienen 1809, erinnert, mit ihrer deutlichen Analogie von menschlichen Beziehungen und chemischen Prozessen. - $\mathrm{Zu}$ diesen interessanten Konstellationen sollte sich die Fachsprachenforschung durchaus berufen fühlen, in interdisziplinärem Zugriff, gerade auch auf die Bezüge zwischen Literaturwissenschaft und Linguistik, weiterführende Untersuchungen - insbesondere auch aus der ihr eigenen Sichtweise auf Fachlichkeit und Fachsprachlichkeit heraus - anzustreben.

48 Kalverkämper (1983b, hier speziell 143 - 149).

49 Möhn / Pelka (1984: 26).

50 Lothar Hoffmann (21985: 64-70) bietet fünf Abstraktionsstufen an (A als "höchste" bis $E$ als "sehr niedrige") mit ihren zugeordneten äußeren Sprachformen von den "künstlichen Symbolen für Elemente und Relationen" bis zur "natürlichen Sprache mit einigen Fachtermini" sowie den fünf Milieus von der "theoretischen Grundlagenwissenschaft" bis zur "Konsumption" und den entsprechenden Kommunikanten (so z.B. bei $A$ : die Wissenschaftler-Wissenschaftler-Kommunikation).

51 Kalverkämper (1990 a).

52 Auf die Tatsache, daß Fachsprachlichkeit eine Textqualität ist, wird ausdrücklich hingewiesen in Kalverkämper (1983 b), hier insbes. S. 127, ausgeführt bis S. 141 unter dem Etikett 'Fach-Textlinguistik' (gegenüber einer dann anschließend zur Seite gestellten 'Fachtext-Linguistik').

53 In diesem Zusammenhang wird interessieren, wie der HSK-Band "Fachsprachen" (s. Hoffmann / Kalverkämper / Wiegand 1992) die Komplexität auflöst: Im Kapitel II. Auffassungen vom Status der Fachsprachen: Existenzformen, Koexistenzformen, Erklärungsformen finden sich zwölf Artikel:

- Die Fachsprachen in der einzelsprachlichen Differenzierung; - Fachsprache als Wissenschaftssprache; - als Institutionensprache; - als Techniksprache; - als Gruppensprache; Fachsprachen und Gemeinsprache; - Fachsprachen und Gruppensprachen; Fachsprachen als Varietäten; - als Subsprachen; - als Funktionalstile; - als Register; Probleme der Statusbestimmung von Fachsprachen.

54 Vgl. Biere (1989) sowie die verdienstvolle Bibliographie von Biere (1991); Klein (1984); Raible (1978); Rickheit (1995); Spillner [Hrsg.] (1995).

55 Vgl. Groeben / Christmann (1989: 166 f.); Groeben (1982: 173 ff.); Biere (1989: 34 - 41).

56 Vgl. Christmann (1989); Biere (1989).

57 Hierzu sei verwiesen auf die Bibliographie von Kretzenbacher (1992); s. auch Schröder (1995).

$58 \mathrm{Zu}$ diesem Modellumfeld gehört der vergleichbare theoretisch-deduktive Entwurf das "Verständlichkeitskonstrukt" - von Groeben (1978) sowie die daraus weiterent- 
wickelten Techniken der Textoptimierung (Groeben 1982); hierzu s. Groeben / Christmann (1989: 170) oder Biere (1989: 41 - 62).

59 Eine solche Methodik bieten Becker / Jäger / Michaeli / Schmalen (1990) an. Die Kritik ist formuliert bei Kalverkämper (1992 b).

60 Kalverkämper / Weinrich [Hrsg.] (1986), hier insbesondere Teil II.: Wissenschaftsdeutsch - gutes Deutsch?

61 Gauger (1986: 123).

62 Und sie betont zu Recht: "Sie enthalten Faktoren, die man auch in den Konversationsmaximen des Philosophen Grice (1975: 45) findet, und zwar in bezug auf Quantität, Qualität, Beziehung und Verhaltensweise: man soll so informativ wie erforderlich sein, die Wahrheit sagen, relevant sein und verständlich."

63 Ehemals West-Berlin, offiziell aufgelöst zum Jahresende 1990.

64 Hierzu sei verwiesen auf den Band von Krings [Hrsg.] (1996). - Inzwischen gibt es auch eine eigene Buchreihe zu dem Thema: Technical Writing. Beiträge zur Technikdokumentation in Forschung, Ausbildung und Industrie. Hrsg. von Friedrich Knilli / Gabriele Bock / Claus Noack. (Frankfurt/M. - Berlin - Bern - New York - Paris - Wien: Lang 1993 [Band 1] ff.).

65 Mit Krings [Hrsg.] (1996) sind hier illustrierend anzuführen: das Erstellen von Dokumentationen über technische Geräte, Systeme und Anlagen aller Art (Gebrauchsanweisungen, Montage- und Reparaturanleitungen, Hard- und Software-Handbücher, technische Produktbeschreibungen, Wartungsunterlagen bis hin zur Gesamtdokumentation von Großgeräten und Produktionsanlagen). Krings gibt an, daß nach Schätzungen von Insidern der Gesamtbedarf in Deutschland bei mehreren Zehntausend Technischen Redakteuren/Redakteurinnen liegt. Während die Ausbildung in den USA sehr breit etabliert ist, gibt es in Deutschland, gestützt durch Linguistik und Psychologie, ein Profil erst in Anfängen durch die Lehre in Terminologiewissenschaft im Rahmen des Übersetzerstudiums. Aufbau-Studiengänge sowie Bemühungen um die Einrichtung von Studiengängen gibt es zur Zeit an etlichen deutschen Hochschulen, die sich von ihrem Selbstverständnis als technisch oder praktisch oder fachterminologisch oder berufsbezogen her für spezifisch sensibel für diese Herausforderungen gehalten haben; bei Krings (1992) finden sich mit weiteren Aufsätzen verschiedener Autoren zum Thema vorgestellt: TH Aachen, TU Berlin, FH Hannover, Universität Hildesheim, FH Karlsruhe, Universität-GHS Paderborn; auch an das SISIB - Siegener Institut für Sprachen im Beruf an der Universität-Gesamthochschule Siegen wäre zu denken, ebenso wie an ein aktuelles (1995/1996) Modellprojekt zur wissenschaftlichen Weiterbildung im Bereich des Technical Writing am Fachbereich Angewandte Sprachund Kulturwissenschaft der Universität Mainz in Germersheim; vgl. auch generell die einschlägigen Beiträge in Spillner [Hrsg.] (1992). Terminologisch ist das neue Gebiet mit seiner hohen gesellschaftlichen Relevanz noch nicht ganz klar situiert: 'Technische Kommunikation', 'Technisches Schreiben', 'Schreiben in der Technik', als englischer Ausdruck Technical Writing, 'Technische Dokumentation' werden verwendet.

66 Die Informationsgemeinschaft von (verbal-schriftlichem/mündlichem) Text und Bild gilt terminologisch als 'Dokument'. Bilder im weitesten Sinne gehören definitorisch mit dazu, was die semiotischen Bemühungen der Fachkommunikationsforschung (vgl. Kalverkämper 1993 a) aufnimmt und unterstützt.

67 Kalverkämper (1989: 56).

68 Kalverkämper (1995 a). 


\section{4}

69 Hier läßt der Textverlauf zwei prinzipielle Erklärungsrichtungen zu: Erklärungskontext vor dem zu erklärenden, weil neuen Terminus (dann handelt es sich um eine kataphorische Erklärungsrichtung); Erklärungskontext nach dem Terminus (anaphorische Erklärungsrichtung); und natürlich auch Realisierung beider Erklärungsrichtungen, mit dem Terminus gleichsam in der Mitte. Dazu Kalverkämper (1987 a).

70 Vgl. 2.5.5.; Kalverkämper (1995 a).

71 Mit einem solchen weiten, eben nicht nur lexikologisch verengten Begriff von 'Neologismus' auf "neues Wort", zudem in einem systematischen Zusammenhang des Phänomens der 'Neuheit', also eben auch mit 'Archaismen', 'Dialektismen', 'Fremdwörtern', 'Termini', 'Warenzeichen' sowie 'Eigennamen' beschäftigt sich in kommunikativer und textueller Sicht Kalverkämper (1987 b).

72 In diesem Zusammenhang ist es von hoher Signifikanz, daß (das gerade gebrauchte Wort) 'prägen' im Griechischen ja etwas mit der Deutung - modern gesagt: mit der Modellierung - der Wirklichkeit zu tun hat: diese Wirklichkeit wird nämlich typisiert, handwerklich geprägt wie eine Münze (griech. $\tau$ 'v $\tau \tau \varepsilon \imath v, t$ 'yptein 'schlagen', 'stoßen') im Prägestock, der ein Bild einschlägt und geformt hinterläßt (griech. $\tau$ ' $\pi_{0} \varsigma$, typos 'Hieb', 'Schlag', 'Prägung'). '

73 Gerade auch aus der Sicht von Wissenschaftsjournalisten. Vgl. Kreuzer [Hrsg.] (1980); Ruß-Mohl [Hrsg.] (21987).

74 Vgl. 3.5.

75 Marcus Fabius Quintilianus: “Institutio oratoria. Libri XII." Hier: VIII 2, 13. -

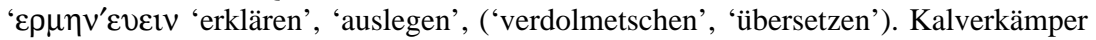
(1988: 158 ff., 160-168; 1995 a).

76 Unter diesen Prämissen ist ein in seiner Konzeption und seiner Realisierung neuartiger Fremdsprachlehrkurs (für das Fernstudium) entstanden, dargestellt in Kalverkämper (1990 b; 1995 b).

77 Vgl. z.B.: Arntz (1992); Göpferich (1995); Snell-Hornby [Hrsg.] (1986); Stolze (1992 a; 1992 b).

78 Ammon (1991, 1992); Gellert-Novak (1993); Kalverkämper / Weinrich [Hrsg.] (1986); Oksaar (1995); Oksaar / Skudlik / von Stackelberg (1988); Skudlik (1990); Weinrich $(1985,1986)$. - Generell s. die ertragreiche Bibliographie von Kretzenbacher (1992).

79 Vgl. z.B. Bossong (1992).

80 Eine Abkehr von der ausschließlich utilitaristischen Bewertung der Einzelsprachen hin zu einer Beachtung der unterschiedlichen Funktionen von Sprachen im Leben der Sprachbenutzer ist durch Harald Weinrich angestoßen und gemeinsam mit anderen fremdsprachenpolitisch Engagierten in den "Homburger Empfehlungen für eine sprachteilige Gesellschaft" formuliert worden (s. Christ / u.a. [Hrsg.] 1980). Dort wird in einer weltoffenen Grundhaltung unterschieden nach "Begegnungssprachen" (Begegnung mit Zweitsprachen im spielerischen, alltagskommunikativen Miteinander; mit dem Effekt der Einübung fremdkultureller Toleranz); dann "Fundamentalsprachen" (als erste Fremdsprache in der Schule, wohl klar zu wählen unter dem Aspekt des hohen Kulturprestiges, wobei auf Englisch im Vordergrund auch noch Französisch und Latein aufrücken sollten); des weiteren "Verkehrssprachen" (mit großer "Reichweite" als Angebot der zweiten Schulsprache, worunter Englisch, durchaus auch Spanisch fallen); schließlich "Erschließungssprachen" (entfernte Fremdsprachen wie Arabisch oder Chinesisch als Erfahrung gänzlich anderer Kulturkreise). 
81 Das als solches sich in Gegensatz stellt zu einer statisch verstandenen TextsortenTaxonomik wie z.B. bei Gläser (1990).

$82 \mathrm{Zu}$ denken ist insbesondere an die Interkulturelle Wirtschaftskommunikation, wie sie ja auch bereits institutionalisiert ist (z.B. an den Universitäten Bayreuth oder Jena); s. z.B. Müller [Hrsg.] (21993).

83 So zum fachlichen Bild oder zur fachbezogenen Körpersprache: Kalverkämper (1993 a).

84 Hier ist auf terminologischer Ebene hinzuweisen z.B. auf Budin (1996), auf textueller Ebene z.B. auf Jahr (1996).

85 Hierzu Kalverkämper (1993 b).

86 Hier ist Gelegenheit, auf den leider in Vergessenheit geratenen Olschki (19181927) hinzuweisen.

87 Erwähnenswert sind z.B. Jakob (1991) oder Schrader (1990).

88 S. 2.5.3. - Technical Writing, damit zusammenhängend: neue Berufsbilder wie Technischer Redakteur, Dokumentarist oder Wissenschaftsjournalist.

89 Hierzu empfiehlt sich die Bibliographie von Becker-Mrotzek (1992).

90 So die deutliche Bevorzugung von Fachsprachen in den Sprachausbildungsprogrammen von Lehrinstituten wie Goethe-Institut, DAAD-Sprachvermittlung, kommerziellen Unternehmen (Berlitz, Langenscheidt etc.); außerdem das ausdrückliche Betonen der Multilingualität. Vgl. Buhlmann / Fearns (1987); Fluck (1992); Gnutzmann [Hrsg.] (1988).

91 Der Bedarf an einer philosophisch-ethischen Begleitung, ja Inspektion der Verantwortung und Verantwortlichkeit von Natur- und Geisteswissenschaften und ihrer Auswirkungen auf die gesellschaftlichen Prozesse manifestiert sich nicht zuletzt an der Einrichtung einer thematisch einschlägigen Buch-Reihe: Ethik der Wissenschaften. Hrsg. von Hans Lenk / Hansjürgen Staudinger / Elisabeth Ströker. (München Paderborn - Wien - Zürich: Fink / Schöningh 1984 [Band 1] ff.). - Vgl. Baumgartner / Staudinger [Hrsg.] (1985); Böhme / von Engelhardt [Hrsg.] (1979); Good [Hrsg.] (1982); Lenk (1992); Riesenhuber (1995); Ströker [Hrsg.] (1984).

92 S. hierzu Lohmeyer (1984); Bullinger [Hrsg.] (1994).

93 Der Wissenschaftsjournalismus ist - wie das Technical Writing, die Textoptimierung im Rahmen der Technischen Kommunikation - ein ganz wichtiges und breitenerzieherisches wie auch allgemeinbildendes Werkzeug für die gesellschaftliche Kommunikation und die möglichst viele soziale Gruppen erfassende Akzeptanz fachlicher Gegebenheiten, Geschehnisse, Entwicklungen, Zukunfsaussichten. Nicht ohne Grund gibt es einen weiter expandierenden Markt an einschlägigen Zeitschriften (wie Spektrum der Wissenschaft, Bild der Wissenschaft, Wissenschaft und Forschung usw.); des weiteren ist auch hier wieder das Sachbuch mit seinem verantwortungsvollen Stellenwert in der fachexternen Kommunikation zu erwähnen (vgl. 2.5.3., 2.5.5.). Hierzu als Anweisung interessant Ruß-Mohl [Hrsg.] (21987).

94 Kalverkämper (1992 c; 1993 a); Baumann / Kalverkämper (1995: 273).

95 Ich darf hinweisen auf die Bezüge, die in Kalverkämper (1994) thematisiert sind.

96 Hierzu sei nochmals (s. 3.2.) auf Müller [Hrsg.] (21993) verwiesen.

97 Hierzu die einschlägigen Informationen in Kalverkämper (1995 c).

98 Für die Fachsprachenforschung dürfte hierzu der Band Baumann / Kalverkämper [Hrsg.] (1992) den Stellenwert für sich beanspruchen, die Kontrastivität als Thema 
erstmals und umfassend angegangen zu sein (übrigens auf der Ersten Gesamtdeutschen Fachsprachenkonferenz im Oktober 1991 in Leipzig).

99 Hierzu Raible (1980) und Kalverkämper (1983 c).

100 "[Le texte] est une permutation de textes, une intertextualité: dans l'espace d'un texte plusieurs énoncés, pris d'autres textes, se croisent et se neutralisent." (Kristeva 1969).

101 Kristeva (1969); zuden auch Lachmann (1984) und Stierle (1984). Als Bibliographie zu diesem vielstrapazierten Begriff s. Hebel (1989).

102 Vgl. Kocka [Hrsg.] (1987).

103 Hierzu Schmidt (1975).

104 Zur Diskussion tragen bei: Kreuzer [Hrsg.] (1987) und Lepenies (1985).

105 Über Fluck (1992) hinausgehend gefordert bei Kalverkämper (1995 c).

106 Hinnenkamp (1994) als Bibliographie zum Thema. Vgl. auch Fußnote 29 unter Kapitel 2.1.

107 Es ist überlegenswert und je nach Argumentation durchaus sinnvoll, statt des statischen Begriffs 'Kultur' in diesem Zusammenhang eine dynamische Fassung zu wählen: hier wäre dann zu denken an 'Kulturbindung' oder, in neutraler Sicht auf das Phänomen, an 'Kultureinbettung'.

\section{Literaturverzeichnis}

Albrecht, Jörn / Baum, Richard [Hrsg.] (1992): Fachsprache und Terminologie in Geschichte und Gegenwart. Tübingen: Narr. (= Forum für FachsprachenForschung. 14).

Ammon, Ulrich (1991): Die internationale Stellung der deutschen Sprache. Berlin New York: de Gruyter.

- (1992): “Deutsch als Wissenschaftssprache.” In: Spektrum der Wissenschaft, Heft 1 (Januar), 117 - 124.

Arntz, Reiner (1992): "Interlinguale Vergleiche von Terminologien und Fachtexten." In: Baumann / Kalverkämper [Hrsg.] (1992: 108 - 122).

Assion, Peter (1973): Altdeutsche Fachliteratur. Berlin: Schmidt. (= Grundlagen der Germanistik. 13).

Baumann, Klaus-Dieter (1992): Integrative Fachtextlinguistik. Tübingen: Narr. (= Forum für Fachsprachen-Forschung. 18).

Baumann, Klaus-Dieter / Kalverkämper, Hartwig [Hrsg.] (1992): Kontrastive Fachsprachenforschung. Tübingen: Narr. (= Forum für Fachsprachen-Forschung. 20).

- / - (1995): "Fachsprachliche Kommunikation.” In: Spillner [Hrsg.] (1995: 269 - 274).

Baumgartner, Hans Michael / Staudinger, Hansjürgen [Hrsg.] (1985): Entmoralisierung der Wissenschaften? Physik und Chemie. München - Paderborn - Wien - Zürich: Fink / Schöningh. (= Ethik der Wissenschaften. 1).

Becker, Thomas / Jäger, Ludwig / Michaeli, Walter / Schmalen, Heinrich [Hrsg.] (1990): Sprache und Technik. Gestalten verständlicher technischer Texte. Konzepte, 
Probleme, Erfahrungen. Aachen: Alano Verlag / Rader Publikationen.

Becker-Mrotzek, Michael (1992): Diskursforschung und Kommunikation in Institutionen. Heidelberg: Groos. (= Studienbibliographien Sprachwissenschaft. 4).

Biere, Bernd Ulrich (1989): Verständlich-Machen. Hermeneutische Tradition Historische Praxis - Sprachtheoretische Begründung. Tübingen: Niemeyer. (= Reihe Germanistische Linguistik. 92).

- (1991): Textverstehen und Textverständlichkeit. Heidelberg: Groos. (= Studienbibliographien Sprachwissenschaft. 2).

Böhme, Gernot / von Engelhardt, Michael [Hrsg.] (1979): Entfremdete Wissenschaft. Frankfurt/M.: Suhrkamp. (= Suhrkamp Taschenbuch Wissenschaft. 278).

Böhme, Günther (1984): Bildungsgeschichte des frühen Humanismus. Darmstadt: Wissenschaftliche Buchgesellschaft.

- (1986): Bildungsgeschichte des europäischen Humanismus. Darmstadt: Wissenschaftliche Buchgesellschaft.

Bossong, Georg (1992): "Form und Inhalt in der Europäisierung nicht-europäischer Kultursprachen.” In: Albrecht/Richard [Hrsg.] (1992: 79 - 114).

Broich, Ulrich / Pfister, Manfred [Hrsg.] (1985): Intertextualität. Formen, Funktionen, anglistische Fallstudien. Tübingen: Niemeyer. (= Konzepte der Sprach- und Literaturwissenschaft. 35).

Budin, Gerhard (1996): Wissensorganisation und Terminologie. Die Komplexität und Dynamik wissenschaftlicher Informations- und Kommunikationsprozesse. Tübingen: Narr. (= Forum für Fachsprachen-Forschung. 28).

Buhlmann, Rosemarie / Fearns, Anneliese (1987): Handbuch des Fachsprachenunterrichts. Unter besonderer Berücksichtigung naturwissenschaftlich-technischer Fachsprachen. Berlin - München - Wien - Zürich - New York: Langenscheidt. (= Fremdsprachenunterricht in Theorie und Praxis).

Bullinger, Hans-Jörg [Hrsg.] (1994): Technikfolgenabschätzung (TA). Stuttgart: Teubner. (= Technologiemanagement - Wettbewerbsfähige Technologieentwicklung und Arbeitsgestaltung).

Burkhardt, Armin / Hebel, Franz / Hoberg, Rudolf [Hrsg.] (1989): Sprache zwischen Militär und Frieden: Aufrüstung der Begriffe? Tübingen: Narr. (= Forum für Fachsprachen-Forschung. 7).

Christ, Herbert / u.a. [Hrsg.] (1980): Fremdsprachenpolitik in Europa. Homburger Empfehlungen für eine sprachteilige Gesellschaft. Universität Augsburg.

Christes, Johannes (1975): Bildung und Gesellschaft. Die Einschätzung der Bildung und ihrer Vermittler in der griechisch-römischen Antike. Darmstadt: Wissenschaftliche Buchgesellschaft. (= Erträge der Forschung. 37).

Christmann, Ursula (1989): Modelle der Textverarbeitung: Textbeschreibung als Textverstehen. Münster. (= Arbeiten zur sozialwissenschaftlichen Psychologie. 21).

Clyne, Michael (1987): “Cultural differences in the organization of academic texts." In: Journal of Pragmatics 11, 217 -247. 


\section{8}

- (1993): "Pragmatik, Textstruktur und kulturelle Werte. Eine interkulturelle Perspektive.” In: Schröder [Hrsg.] (1993: 4 - 18).

Curtius, Ernst Robert ( $\left.{ }^{11} 1993\right)$ : Europäische Literatur und lateinisches Mittelalter. 11. Aufl. Tübingen - Basel: Francke. (1. Aufl. 1948).

Deutsche Akademie für Sprache und Dichtung [Darmstadt] (1980-1982): Der öffentliche Sprachgebrauch. I: Die Sprachnorm-Diskussion in Presse, Hörfunk und Fernsehen. Bearb. von Birgitta Mogge. Stuttgart: Klett-Cotta 1980; II: Die Sprache des Rechts und der Verwaltung. Bearb. von Ingulf Radtke. Stuttgart: Klett-Cotta 1981; III: Schulen für einen guten Sprachgebrauch. Bearb. von Birgitta Mogge / Ingulf Radtke. Stuttgart: Klett-Cotta 1982.

Diderot, Denis / D’Alembert, Jean Le Rond [Éds.] (1751-1780): Encyclopédie, ou Dictionnaire raisonné des sciences, des arts et des métiers, par une société de gens de lettres. Mis en ordre \& publié par M. Diderot, de l'Académie Royale des Sciences \& des Belles-Lettres de Prusse; \& quant à la Partie Mathématique, par M. D’Alembert, de l'Académie Royale des Sciences de Paris, de celle de Prusse, \& de la Société Royale de Londres. Paris. Nouvelle impression en facsimilé de la première édition de 1751-1780. I - XXXV. Stuttgart - Bad Cannstatt 1966.

Dolch, Josef (1982): Lehrplan des Abendlandes. Zweieinhalb Jahrtausende seiner Geschichte. Darmstadt: Wissenschaftliche Buchgesellschaft.

Eis, Gerhard (1960): "Mittelalterliche Fachprosa der Artes." In: Stammler, Wolfgang [Hrsg.] (1960): Deutsche Philologie im Aufriss. Band II. 2. überarb. Aufl. Berlin: Schmidt. 1103 - 1216.

- (21967): Mittelalterliche Fachliteratur. 2. Aufl. Stuttgart: Metzlersche Verlagsbuchhandlung. (= Sammlung Metzler. Realienbücher für Germanisten. Abt. D: Literaturgeschichte. M 14).

Fluck, Hans-Rüdiger (1992): Didaktik der Fachsprachen. Aufgaben und Arbeitsfelder, Konzepte und Perspektiven im Sprachbereich Deutsch. Tübingen: Narr. (= Forum für Fachsprachen-Forschung. 16).

Furet, François (1965): "La 'librairie' du royaume de France au $18^{\mathrm{e}}$ siècle." In: Bollème, Geneviève / Ehrard, Jean / Furet, François / Roche, Daniel / Roger, Jaques (1965): Livre et société dans la France du XVIII ${ }^{e}$ siècle. [I.]. Paris - La Haye. (= École Pratique des Hautes Études, Sorbonne. VI ${ }^{\mathrm{e}}$ section: Sciences Économiques et Sociales. - Civilisations et Sociétés. 1). 3 - 32.

Galtung, Johan (1985): "Struktur, Kultur und intellektueller Stil. Ein vergleichender Essay über saxonische, teutonische, gallische und nipponische Wissenschaft." In: Wierlacher [Hrsg.] (1985: 151 - 193). (Wiederabdruck aus: Leviathan 2, 1983, 303 - 338. [Beide als deutsche Version von: "Structure, culture and intellectual style. An essay comparing saxonic, teutonic, gallic and nipponic approaches." In: Social Science Information 20, 1981, 817 - 856.]).

Gauger, Hans-Martin (1986): "Zur Sprache der Wissenschaft. Sermo incurvatus in se ipsum.”In: Kalverkämper / Weinrich [Hrsg.] (1986: 119 - 123). 
Gellert-Novak, Anne (1993): Europäische Sprachenpolitik und Euroregionen. Ergebnisse einer Befragung zur Stellung der englischen und deutschen Sprache in Grenzgebieten. Tübingen: Narr. (= Giessener Beiträge zur Fremdsprachendidaktik).

Gläser, Rosemarie (1990): Fachtextsorten im Englischen. Tübingen: Narr. (= Forum für Fachsprachen-Forschung. 13).

Gnutzmann, Claus [Hrsg.] (1988): Fachbezogener Fremdsprachenunterricht. Tübingen: Narr. (= Forum für Fachsprachen-Forschung. 6).

Goez, W. (1958): Translatio Imperii. Ein Beitrag zur Geschichte des Geschichtsdenkens und der politischen Theorien im Mittelalter und in der frühen Neuzeit. Tübingen: Niemeyer.

Good, Paul [Hrsg.] (1982): Von der Verantwortung des Wissens. Positionen der neueren Philosophie der Wissenschaft. Frankfurt/M.: Suhrkamp. (= Edition Suhrkamp. 1122. [Neue Folge. 122]).

Göpferich, Susanne (1995): Textsorten in Naturwissenschaften und Technik. Pragmatische Typologie - Kontrastierung - Translation. Tübingen: Narr. (= Forum für Fachsprachen-Forschung. 27).

Greimas, Algirdas Julien (1970): "La structure sémantique.” In: Greimas, Algirdas Julien (1970): Du sens. Paris. 39 - 48.

Groeben, Norbert (1982): Leserpsychologie: Textverständnis - Textverständlichkeit. Münster: Aschendorff.

Groeben, Norbert / Christmann, Ursula (1989): “Textoptimierung unter Verständlichkeitsperspektive.” In: Antos, Gerd / Krings, Hans P. [Hrsg.] (1989): Textproduktion: ein interdisziplinärer Forschungsüberblick. Tübingen: Niemeyer. (= Konzepte der Sprach- und Literaturwissenschaft. 48). 165 - 196.

Gulley, Norman (1962): Plato's Theory of Knowledge. London: Methuen.

Hard, Gerhard (1970): Die "Landschaft" der Sprache und die "Landschaft" der Geographen. Semantische und forschungslogische Studien zu einigen zentralen Denkfiguren in der deutschen geographischen Literatur. Bonn: Dümmlers Verlag. (= Colloquium Geographicum. 11).

Hebel, Udo J. (1989): Intertextuality. Allusion, and Quotation. An International Bibliography of Crictical Studies. New York. (= Bibliographies and Indexes in Word Literature. 18).

Hinnenkamp, Volker (1994): Interkulturelle Kommunikation. Heidelberg: Groos. (= Studienbibliographien Sprachwissenschaft. 11).

Hoffmann, Lothar (21985): Kommunikationsmittel Fachsprache. Eine Einführung. 2. völlig neu bearb. Aufl. Tübingen: Narr. (= Forum für Fachsprachen-Forschung. 1).

- (1988): Vom Fachwort zum Fachtext. Beiträge zur Angewandten Linguistik. Tübingen: Narr. (= Forum für Fachsprachen-Forschung. 5).

Hoffmann, Lothar / Kalverkämper, Hartwig / Wiegand, Herbert Ernst (1992): "Ein neuer Doppelband in der HSK-Reihe entsteht: Fachsprachen / Languages for Special Purposes. - Ein internationales Handbuch zur Fachsprachenforschung und 
Terminologiewissenschaft / An International Handbook of Special Languages and Terminology Research.” In: Fachsprache / International Journal of LSP 14, 48 - 57.

Jahr, Silke (1996): Das Verstehen von Fachtexten. Rezeption - Kognition - Applikation.

Tübingen: Narr. (= Forum für Fachsprachen-Forschung. 34).

Jakob, Karlheinz (1991): Maschine, Mentales Modell, Metapher. Studien zur Semantik und Geschichte der Techniksprache. Tübingen: Niemeyer. (= Reihe Germanistische Linguistik. 123).

Kalverkämper, Hartwig (1982): "Fachsprachen und Textsorten.” In: Høedt, Jørgen / Lundquist, Lita / Picht, Heribert / Qvistgaard, Jacques [Eds.] (1982): Proceedings of the Third European Symposium on Language for Special Purposes 'LSP', Copenhagen 1981: "Pragmatics and LSP”. Copenhagen: Nyt Nordisk Forlag. 105 - 168.

- (1983 a): "Antike Rhetorik und Textlinguistik. Die Wissenschaft vom Text in altehrwürdiger Modernität." In: Faust, Manfred / Harweg, Roland / Lehfeldt, Werner / Wienold, Götz [Hrsg.] (1983): Allgemeine Sprachwissenschaft, Sprachtypologie und Textlinguistik. Festschrift für Peter Hartmann. Tübingen: Narr. (= Tübinger Beiträge zur Linguistik. 215). 349 - 372.

- (1983 b): “Textuelle Fachsprachen-Linguistik als Aufgabe.” In: Kreuzer, Helmut / Schlieben-Lange, Brigitte [Hrsg.] (1983): Fachsprache und Fachliteratur. Göttingen: Vandenhoeck \& Ruprecht. (= Zeitschrift für Literaturwissenschaft und Linguistik 'LiLi' 13, Heft 51/52). 124 - 166.

- (1983 c): "Gattungen, Textsorten, Fachsprachen. Textpragmatische Überlegungen zur Klassifikation.” In: Hess-Lüttich, Ernest W.B. [Hrsg.] (1983): Textproduktion und Textrezeption. Tübingen: Narr. (=forum Angewandte Linguistik. 3). 91 - 103.

- (1987 a): "Vom Terminus zum Text.” In: Sprissler, Manfred [Hrsg.] (1987): Standorte der Fachsprachen-Forschung. Tübingen: Narr. (= forum Angewandte Linguistik. 11). 39 - 78 .

- (1987 b): "Neologismen - Hinterfragung eines linguistischen Konzepts." In: Quaderni di Semantica [Bologna, Italia] 8, 311- 345.

- (1988): "Fachexterne Kommunikation als Maßstab einer Fachsprachen-Hermeneutik. Verständlichkeit kernphysikalischer Fakten in spanischen Zeitungstexten." In: Kalverkämper [Hrsg.] (1988): Fachsprachen in der Romania. Tübingen: Narr. (= Forum für Fachsprachen-Forschung. 7). 151 - 193.

- (1989): "Kolloquiale Vermittlung von Fachwissen im frühen 18. Jahrhundert - gezeigt anhand der Entretiens sur la Pluralité des Mondes (1686) von Fontenelle." In: Schlieben-Lange, Brigitte [Hrsg.] (1989): Fachgespräche in Aufklärung und Revolution. Tübingen: Niemeyer. (= Konzepte der Sprach- und Literaturwissenschaft. 47). 17 - 80.

- (1990 a): "Gemeinsprache und Fachsprachen - Plädoyer für eine integrierende Sichtweise.” In: Stickel, Gerhard [Hrsg.] (1990): Deutsche Gegenwartssprache. Tendenzen und Perspektiven. Jahrbuch 1989 [zum 25jährigen Jubiläum] des Instituts für deutsche Sprache [Mannheim]. Berlin - New York: de Gruyter. 88 - 133. 
- (1990 b): "Kultur- und Wissenschaftssprache Deutsch - Deutsch als Fremdsprache für das Fernstudium in Lateinamerika." In: Fremdsprachen Lehren und Lernen ('FLuL'). Zur Theorie und Praxis des Sprachunterrichts an Hochschulen 19: "Fachsprachen und ihre Vermittlung", 97 - 125.

- (1992 a): "Die kulturanthropologische Dimension von 'Fachlichkeit' im Handeln und Sprechen. Kontrastive Studien zum Deutschen, Englischen, Französischen, Italienischen und Spanischen." In: Albrecht / Baum [Hrsg.] (1992: 31 - 58).

- (1992 b): Rezension zu Becker / Jäger / Michaeli / Schmalen (1990) in: Info DaF. Informationen Deutsch als Fremdsprache 19, Nr. 3, Juni 1992, 389 - 398.

- (1992 c): "Entwurf einer Fachsprachen-Semiotik - Erster Aspekt: Das fachliche Bild."

In: Raasch, Albert / Cuny, Marie-Laure / Bühler, Peter / Magar, Christof [Hrsg.] (1992): Angewandte Linguistik 1992. Saarbrücken: Universität des Saarlandes. (= Saarbrücker Schriften zur Angewandten Linguistik und Sprachlehrforschung. 11). 96.

- (1993 a): "Das fachliche Bild. Zeichenprozesse in der Darstellung wissenschaftlicher Ergebnisse.” In: Schröder [Hrsg.] (1992: 215 - 238).

- (1993 b): "Diachronie in der Fachsprachenforschung - Überlegungen zu Inhalt, Methoden und Zielen." In: Finlance. A Finnish Journal of Applied Linguistics (University of Jyväskylä, Finland) 12: "Diachrone Fachsprachenforschung / Diachronic LSP-Research" (Sabine Ylönen [Ed.]), 18 - 47.

- (1994): "Semiotik und Fachsprachenforschung." In: Zeitschrift für Semiotik 16, Heft 1-2: “Zeit der Hypermedien", 160 - 163.

- (1995 a): "Fachinformationen für Laien in lexikographischen Formen in Texten.” In:

Lexicographica. International Annual for Lexicography / Revue Internationale de Lexicographie / Internationales Jahrbuch für Lexikographie 11: "Fachlexikographie / Lexicography for Special Purposes", 74 - 120.

- (1995 b): “'Deutsch als': Herausforderungen im Disziplinen-Spektrum - Verpflichtungen für die Sprach-, Sach- und Kulturvermittlung." In: Wolff, Armin [Hrsg.] (1995): Tagungsband der 21. Jahrestagung des Fachverbandes Deutsch als Fremdsprache 'fadaf' in Erlangen 1993. Regensburg. (Im Druck).

- (1995 c): "Kultureme erkennen, lehren und lernen - Eine kontrastive und interdisziplinäre Herausforderung an die Forschung und Vermittlungspraxis." In: Fremdsprachen Lehren und Lernen ('FLuL'). Zur Theorie und Praxis des Sprachunterrichts an Hochschulen 24: “Kontrastivität und kontrastives Lernen”, 138 - 181.

- (1996): "Die Kultur des literarischen wissenschaftlichen Dialogs - aufgezeigt an einem Beispiel aus der italienischen Renaissance (Galilei) und der französischen Aufklärung (Fontenelle)." In: Kalverkämper / Baumann [Hrsg.] (1996).

Kalverkämper, Hartwig / Baumann, Klaus-Dieter [Hrsg.] (1996): Fachliche Textsorten. Komponenten - Relationen - Strategien. Tübingen: Narr. (= Forum für Fachsprachen-Forschung. 25).

Kalverkämper, Hartwig / Weinrich, Harald [Hrsg.] (1986): Deutsch als Wissenschaftssprache. Tübingen: Narr. (= Forum für Fachsprachen-Forschung. 3).

Keil, Gundolf / Assion, Peter [Hrsg.] (1974): Fachprosaforschung. Acht Vorträge zur mittelalterlichen Artesliteratur. Berlin: Schmidt. 
Keil, Gundolf / Assion, Peter / Daems, Willem Frans / Roehl, Heinz-Ulrich [Hrsg.] (1982): Fachprosa-Studien. Beiträge zur mittelalterlichen Wissenschafts- und Geistesgeschichte. Berlin: Schmidt.

Klein, Wolfgang [Hrsg.] (1984): Textverständlichkeit - Textverstehen. Göttingen: Vandenhoeck \& Ruprecht. (= Zeitschrift für Literaturwissenschaft und Linguistik ' $L i L i$ ' 14, Heft 55).

Der Kleine Pauly. Lexikon der Antike. Auf der Grundlage von Pauly's Realencyclopädie der classischen Altertumswissenschaft unter Mitwirkung zahlreicher Fachgelehrter bearbeitet und herausgegeben von Konrat Ziegler und Walther Sontheimer. Band 1 - 5. München: Deutscher Taschenbuch Verlag (1979).

Koch, Josef [Hrsg.] (1959): Artes Liberales. Von der antiken Bildung zur Wissenschaft des Mittelalters. Leiden - Köln: Brill. (= Studien und Texte zur Geistesgeschichte des Mittelalters. 5).

Kocka, Jürgen [Hrsg.] (1987): Interdisziplinarität. Praxis - Herausforderung - Ideologie. Frankfurt/M.: Suhrkamp. (= Suhrkamp Taschenbuch Wissenschaft. 671).

Kretzenbacher, Heinz L. (1992): Wissenschaftssprache. Heidelberg: Groos. (= Studienbibliographien Sprachwissenschaft. 5).

Kretzenbacher, Heinz L. / Weinrich, Harald [Hrsg.] (1994): Linguistik der Wissenschaftssprache. Berlin - New York: de Gruyter. (= Akademie der Wissenschaften zu Berlin. Forschungsbericht 10).

Kreuzer, Helmut [Hrsg.] (1980): Sachliteratur. Göttingen: Vandenhoeck \& Ruprecht. (= Zeitschrift für Literaturwissenschaft und Linguistik 'LiLi' 10, Heft 40).

- [Hrsg.] (1987): Die zwei Kulturen. Literarische und naturwissenschaftliche Intelligenz. C.P. Snows These in der Diskussion. München: Deutscher Taschenbuch Verlag. (= dtv / Klett-Cotta. 4454).

Krings, Hans P. (1992): “Themenbereich 'Technische Kommunikation'.” In: Spillner [Hrsg.] (1992: 115 - 138)

- [Hrsg.] (1996): Wissenschaftliche Grundlagen der Technischen Kommunikation. Tübingen: Narr. (= Forum für Fachsprachen-Forschung. 32).

Kristeva, Julia (1969): $\Sigma \eta \mu \varepsilon \imath \omega \tau \imath \kappa^{\prime} \eta$. Recherches pour une sémanalyse. Essais. Paris. (= Tel Quel).

Krusche, Dietrich / Wierlacher, Alois [Hrsg.] (1990): Hermeneutik der Fremde. München: Iudicium.

Lachmann, Renate (1984): "Ebenen des Intertextualitätsbegriffs". In: Stierle, Karlheinz / Warning, Rainer [Hrsg.] (1984): Das Gespräch. München: Fink. (= Poetik und Hermeneutik. XI). 133-138.

Langer, Inghard / Schulz von Thun, Friedemann / Tausch, Reinhard (21981): Sich verständlich ausdrücken. 2., völlig neubearb. Aufl. von Verständlichkeit in Schule, Verwaltung, Politik und Wissenschaft. München - Basel: Reinhardt.

Lausberg, Heinrich (1960): Handbuch der literarischen Rhetorik. Eine Grundlegung der Literaturwissenschaft. München: Hueber. $\left({ }^{3} 1989\right)$.

Lenk, Hans (1992): Zwischen Wissenschaft und Ethik. Frankfurt/M.: Suhrkamp. (= Suhrkamp Taschenbuch Wissenschaft. 980). 
Lepenies, Wolf (1985): Die drei Kulturen. Soziologie zwischen Literatur und Wissenschaft. München - Wien: Hanser.

Lexicon Iconographicum Mythologiae Classicae 'LIMC'. Zürich: Artemis. Band III/1: 1986; Band VII/1: 1994.

Lexikon der christlichen Ikonographie 'LCI'. Herausgegeben von Engelbert Kirschbaum in Zusammenarbeit mit [...]. Band 1 - 4: Allgemeine Ikonographie. Rom - Freiburg im Br. - Basel - Wien: Herder 1990 (Sonderausgabe).

Linfert, Andreas (1976): Kunstzentren hellenistischer Zeit. Studien an weiblichen Gewandfiguren. Mit 73 Tafeln. Wiesbaden: Steiner.

Lohmeyer, Jürgen (1984): Technology Assessment: Anspruch, Möglichkeiten und Grenzen. Untersuchungen zum Problemkreis der Technikfolgen-Abschätzung unter besonderer Berücksichtigung des sozialwissenschaftlichen Beitrages. Diss. Bonn.

Meier, Chr. (1975): "Fortschritt II: 'Fortschritt' in der Antike.” In: Brunner, O. / Conze, W. / Koselleck, R. [Hrsg.] (1975): Geschichtliche Grundbegriffe. Historisches Lexikon zur politisch-sozialen Sprache in Deutschland. II. Stuttgart. 353 - 363.

Merton, Robert K. (1983): Auf den Schultern von Riesen. Ein Leitfaden durch das Labyrinth der Gelehrsamkeit. Aus dem Amerikanischen von Reinhard Kaiser. Frankfurt/M.: Suhrkamp. (= Suhrkamp-Taschenbuch Wissenschaft. 426).

Möhn, Dieter / Pelka, Roland (1984): Fachsprachen. Eine Einführung. Tübingen. Niemeyer (= Germanist. Arbeitshefte 30).

Müller, Bernd-Dietrich [Hrsg.] (21993): Interkulturelle Wirtschaftskommunikation. 2., überarb. und erw. Aufl. München: Iudicium. (= Studium Deutsch als Fremdsprache - Sprachdidaktik. 9). (1. Aufl. 1991).

Müller, Gregor (1969): Bildung und Erziehung im Humanismus der italienischen Renaissance. Grundlagen - Motive - Quellen. Wiesbaden: Steiner.

Munsberg, Klaus (1994): Mündliche Fachkommunikation. Das Beispiel Chemie. Tübingen: Narr. (= Forum für Fachsprachen-Forschung. 21).

Oksaar, Els (1986): "Gutes Wissenschaftsdeutsch - Perspektiven der Bewertung und der Problemlösungen.” In: Kalverkämper / Weinrich [Hrsg.] (1986: 100 - 118).

- (1988): Fachsprachliche Dimensionen. Tübingen: Narr. (= Forum für FachsprachenForschung. 4).

Oksaar, Els / Skudlik, Sabine / von Stackelberg, Jürgen (1988): Gerechtfertigte Vielfalt. Zur Sprache in den Geisteswissenschaften. Antworten auf die Preisfrage der Deutschen Akademie für Sprache und Dichtung vom Jahr 1986: 'Ist eine internationale Gemeinsprache auch in den Geisteswissenschaften möglich und wünschenswert?'. Mit einem Nachwort von Hans-Martin Gauger. Darmstadt: Luchterhand Literaturverlag.

Olschki, Leonardo (1918 - 1922 - 1927): Geschichte der neusprachlichen wissenschaftlichen Literatur. - I.: Die Literatur der Technik und der angewandten Wissenschaften vom Mittelalter bis zur Renaissance. Heidelberg: Winter 1918. - II.: Bildung und Wissenschaft im Zeitalter der Renaissance in Italien. Leipzig - Firenze 
- Roma - Genève: Olschki 1922. - III.: Galilei und seine Zeit. Halle (Saale): Niemeyer 1927.

Pauly's Real-Encyclopädie der classischen Altertumswissenschaft. Stuttgart 1927 ff.

Pörksen, Uwe (1986): Deutsche Naturwissenschaftssprachen. Historische und kritische Studien. Tübingen: Narr. (= Forum für Fachsprachen-Forschung. 2).

- (1994): Wissenschaftssprache und Sprachkritik. Untersuchungen zu Geschichte und Gegenwart. Tübingen: Narr. (= Forum für Fachsprachen-Forschung. 22).

Raible, Wolfgang (1978): "Lange Rede dunkler Sinn. Zur Verständlichkeit von Texten aus der Sicht der Sprachwissenschaft.” In: Engel, Ulrich / Grosse, Siegfried [Hrsg.] (1978): Grammatik und Deutschunterricht. Jahrbuch 1977 des Instituts für deutsche Sprache [Mannheim]. Düsseldorf: Schwann. (= Sprache der Gegenwart. XLIV). $316-337$.

- (1980): "Was sind Gattungen? Eine Antwort aus semiotischer und textlinguistischer Sicht.” In: Poetica. Zeitschrift für Sprach- und Literaturwissenschaft 12, 320 - 349.

- (1981): "Rechtssprache - Von den Tugenden und Untugenden einer Fachsprache.” In: Deutsche Akademie für Sprache und Dichtung [Darmstadt] (1980-1982: II [1981]: $20-43)$.

Rickheit, Gert (1995): "Verstehen und Verständlichkeit von Sprache." In: Spillner [Hrsg.] (1995: 15 - 30).

Riesenhuber, Heinz (1995): Ethik in Wissenschaft und Technik. Heidelberg: Müller Juristischer Verlag. (= Schriftenreihe Juristische Studiengesellschaft Karlsruhe. 214).

Ruß-Mohl, Stephan [Hrsg.] (21987): Wissenschafts-Journalismus. Ein Handbuch für Ausbildung und Praxis. 2., aktualisierte Aufl. München: List. (= List. Journalistische Praxis). (1. Aufl. 1986).

Schalk, Fritz (1968): “Zur Semantik von 'Aufklärung' in Frankreich.” In: Baldinger, Kurt [Hrsg.] (1968): Festschrift Walther von Wartburg zum 80. Geburtstag, 18. Mai 1968. I. Tübingen: Niemeyer. 251 - 266.

Schiffler, Horst / Winkeler, Rolf ( $\left.{ }^{3} 1991\right)$ : Tausend Jahre Schule. Eine Kulturgeschichte des Lernens in Bildern. 3. Aufl. Stuttgart - Zürich: Belser. (1. Aufl. 1985).

Schmidt, Siegfried J. (1975): Zum Dogma der prinzipiellen Differenz zwischen Naturund Geisteswissenschaft. Göttingen: Vandenhoeck \& Ruprecht. (= Veröffentlichung der Joachim Jungius-Gesellschaft der Wissenschaften).

Schrader, Norbert (1990): Termini zwischen wahrer Natur und willkürlicher Bezeichnung. Exemplarische Untersuchungen zur Theorie und Praxis historischer Wissenschaftssprache. Tübingen: Niemeyer. (= Reihe Germanistische Linguistik. 105).

Schröder, Hartmut [Ed.] (1991): Subject-oriented Texts. Languages for Special Purposes and Text Theory. Berlin - New York: de Gruyter. (= Research in Text Theory - Untersuchungen zur Texttheorie. 16).

- [Hrsg.] (1993): Fachtextpragmatik. Tübingen: Narr. (= Forum für FachsprachenForschung. 19). 
- (1995): "Der Stil wissenschaftlichen Schreibens zwischen Disziplin, Kultur und Paradigma - Methodologische Anmerkungen zur interkulturellen Stilforschung." In: Stickel, Gerhard [Hrsg.] (1995): Stilfragen. Jahrbuch 1994 des Instituts für deutsche Sprache [Mannheim]. Berlin - New York: de Gruyter. 150 - 180.

Seiffert, Leslie: "Von Fremd- und Lehnwörtern und von Kunst- und anderen auserlesenen Deutungs-reichen [sic!] Wörtern, oder: Darf man doch noch zu einer Elften Lobrede ansetzen?" In: Stickel, Gerhard [Hrsg.] (1990): Deutsche Gegenwartssprache. Tendenzen und Perspektiven. Jahrbuch [zum 25jährigen Jubiläum] des Instituts für deutsche Sprache [Mannheim] 1989. Berlin - New York: de Gruyter. $302-336$.

Shapiro, Harvey A. (1993): Personifications in Greek art: The representation of abstract concepts 600 - 400 B.C. Akanthus.

Skudlik, Sabine (1990): Sprachen in den Wissenschaften. Deutsch und Englisch in der internationalen Kommunikation. Tübingen: Narr. (= Forum für FachsprachenForschung. 10).

Snell, Bruno (1924): Die Ausdrücke für den Begriff des Wissens in der vorplatonischen Philosophie. Berlin: Weidmannsche Buchhandlung. (= Philologische Untersuchungen. 29).

Snell-Hornby, Mary [Hrsg.] (1986): Übersetzungswissenschaft - eine Neuorientierung. Zur Integrierung von Theorie und Praxis. Tübingen: Francke. (= UTB UniTaschenbücher. 1415).

Spillner, Bernd [Hrsg.] (1992): Wirtschaft und Sprache. Kongreßbeiträge zur 22. Jahrestagung der Gesellschaft für Angewandte Linguistik GAL, [Mainz 1991]. Frankfurt/M. - Berlin - Bern - New York - Paris - Wien: Lang. (= forum Angewandte Linguistik. 23).

- [Hrsg.] (1995): Sprache: Verstehen und Verständlichkeit. Kongreßbeiträge zur 25. Jahrestagung der Gesellschaft für Angewandte Linguistik GAL, [Trier 1994]. Frankfurt/M. - Berlin - Bern - New York - Paris - Wien: Lang. (=forum Angewandte Linguistik. 28).

Stierle, Karlheinz (1984): “Werk und Intertextualität." In: Stierle, Karlheinz / Warning, Rainer [Hrsg.] (1984): Das Gespräch. München: Fink. (= Poetik und Hermeneutik. XI). 139-150.

Stolze, Radegundis (1992 a): Hermeneutisches Übersetzen. Linguistische Kategorien des Verstehens und Formulierens beim Übersetzen. Tübingen: Narr.

- (1992 b): "Rechts- und Sprachvergleich beim Übersetzen juristischer Texte." In: Baumann / Kalverkämper [Hrsg.] (1992: 223 - 230).

Stötzel, Georg / Wengeler, Martin (1995): Kontroverse Begriffe. Geschichte des öffentlichen Sprachgebrauchs in der Bundesrepublik Deutschland. In Zusammenarbeit mit Karin Böke / Hildegard Gorny / Silke Hahn / Matthias Jung / Andreas Musolff / Cornelia Tönnesen. Berlin - New York: de Gruyter. (= Sprache, Politik, Öffentlichkeit. 4). 
Strauß, Gerhard / Haß, Ulrike / Harras, Gisela (1989): Brisante Wörter von Agitation bis Zeitgeist. Ein Lexikon zum öffentlichen Sprachgebrauch. Berlin - New York: de Gruyter. (= Schriften des Instituts für deutsche Sprache. 2).

Strauß, Gerhard / Zifonun, Gisela (1985): Die Semantik schwerer Wörter im Deutschen. Teil 1: Lexikologie schwerer Wörter. Teil 2: Typologie und Lexikographie schwerer Wörter. Tübingen: Narr. (= Forschungsberichte des Instituts für deutsche Sprache, Mannheim. 58, 1/2).

Ströker, Elisabeth [Hrsg.] (1984): Ethik der Wissenschaften? Philosophische Fragen. München - Paderborn - Wien - Zürich: Fink / Schöningh. (= Ethik der Wissenschaften. 2).

Trier, Jost (1951): Lehm. Etymologien zum Fachwerk. Marburg: Simons. (= Münstersche Forschungen. 3).

Weinrich, Harald (1985): Wege der Sprachkultur. Stuttgart: Deutsche Verlags-Anstalt.

- (1986): "Sprache und Wissenschaft.” In: Kalverkämper / Weinrich [Hrsg.] (1986: 183 - 193).

- (1988): “Formen der Wissenschaftssprache." In: Jahrbuch der Akademie der Wissenschaften zu Berlin [ehem. West]. Berlin - New York: de Gruyter. 119-158

Wierlacher, Alois [Hrsg.] (1985): Das Fremde und das Eigene. München: Iudicium. 
